\title{
IV. GEOPHYSICAL PROFILING, DSDP 42A
}

\author{
Gerald W. Bode, Scripps Institution of Oceanography, Deep Sea Drilling Project, La Jolla, California
}

\section{INTRODUCTION}

We obtained routine geophysical measurements during Leg $42 \mathrm{~A}$ of the Deep Sea Drilling Project. Of the 841 nautical miles covered from Malaga, Spain, to Istanbul, Turkey, geophysical data were collected on all but the Bosporus Straits, and a short distance approaching them. We were underway 35 per cent of the time during the 41 days spent at sea. Careful planning and excellent geophysical survey data aided us in locating the sites with a minimum expenditure of time. At a few sites strong winds and currents caused problems in positioning the ship over the site.

The onboard instrumentation included a precision echo sounder, magnetometer, seismic reflection profiler, and a satellite navigation system. They were maintained and operated by the Deep Sea Drilling Project's technical staff in cooperation with the scientific party and the officers and crew of Global Marine, Inc.

\section{NAVIGATION}

A Magnavox Model MX702A-3 Satellite Navigation Receiver with an H-P 2100A computer was the main source for navigation information. The unit was used to automatically obtain edited fixes during the cruise. Celestial fixes were also routinely taken by the ship's officers.

The preliminary ship's track was determined by the bridge officers from readings of the gyro-compass and speed estimate (dead reckoning techniques) between satellite fixes. This track was subsequently edited and smoothed. The smoothed track was digitized and speeds and courses-made-good calculated. This information is listed in Table 1.

The accuracy of the track is variable but is \pm 40 meters in the area of a satellite fix. The accuracy is some- what less in other areas depending upon the length of time between fixes, weather and currents, and the maneuvering of the ship.

Strong winds and currents in the vicinity of Site 372 caused some degregation in the navigational control. The smooth track is shown in Figure 1.

\section{Bathymetry}

Bathymetric profiles were obtained with a $16-\mathrm{kHz}$ echo sounder using an EDO recorder. The pulse width is 0.2 milliseconds and the sweep rate was one second. The topographic profile was drawn on the basis of depth readings, taken at 5-minute intervals. This profile is found at the bottom of Figure 2.

\section{Magnetics}

Total intensity measurements of the earth's magnetic field were obtained using a Geometrics magnetometer; the sensor was towed approximately 300 meters astern. In addition to an analog record, actual gamma counts were logged at 5-minute intervals. These digited values were then used to calculate the residual anomalies. The magnetic profile is found at the top of Figure 2.

\section{Seismic Reflecting Profile}

The seismic reflection profiles were obtained utilizing two (10 cubic inches and 40 cubic inches) Bolt pneumatic airguns. The Teledyne hydrophone array was towed approximately 330 meters behind the vessel. The return signals were passed through two Bolt PA6 amplifiers and filter modules before being recorded on two EDO Western Model 550 Precision Bathymetric recorders. Our recorder was set on a 10 second sweep; the other on a 5-second sweep. The annotated 10-second sweep records are shown in Figure 3. 
TABLE 1

\begin{tabular}{lcccc}
\hline Time $\quad$ Latitude & Longitude & $\begin{array}{c}\text { Distance } \\
\text { (miles) }\end{array}$ & $\begin{array}{c}\text { Speed } \\
(\mathrm{knots})\end{array}$ & $\begin{array}{c}\text { Course } \\
\text { (degrees) }\end{array}$ \\
\hline
\end{tabular}

Depart Malaga (14 April 1975)

$\begin{array}{llllrll}1908 & 36^{\circ} 39.20^{\prime} \mathrm{N} & -1^{\circ} & 51.50^{\prime} \mathrm{W} & 0.0 & 6.6 & 86 \\ 1915 & 36^{\circ} 39.30^{\prime} \mathrm{N} & -1^{\circ} & 50.50^{\prime} \mathrm{W} & 0.8 & 9.5 & 85 \\ 2044 & 36^{\circ} 40.40^{\prime} \mathrm{N} & -1^{\circ} & 33.10^{\prime} \mathrm{W} & 14.8 & 9.6 & 83 \\ 2215 & 36^{\circ} 42.30^{\prime} \mathrm{N} & -1^{\circ} & 15.00^{\prime} \mathrm{W} & 29.4 & 9.6 & 79 \\ 2232 & 36^{\circ} 42.80^{\prime} \mathrm{N} & -1^{\circ} & 11.70^{\prime} \mathrm{W} & 32.1 & 9.3 & 82\end{array}$

\section{(15 April 1975)}

\begin{tabular}{|c|c|c|c|c|c|}
\hline 000 & $36^{\circ} 44.80^{\prime} \mathrm{N}$ & $0^{\circ}-54.80^{\prime} \mathrm{W}$ & 45.8 & 9.3 & 82 \\
\hline 0024 & $36^{\circ} 45.30^{\prime} \mathrm{N}$ & $0^{\circ}-50.29^{\prime} \mathrm{W}$ & 49.6 & 8.8 & 80 \\
\hline 0250 & $36^{\circ} 49.20^{\prime} \mathrm{N}$ & $0^{\circ}-23.99^{\prime} \mathrm{W}$ & 71.0 & 8.9 & 83 \\
\hline 0434 & $36^{\circ} 51.00^{\prime} \mathrm{N}$ & $0^{\circ}-4.89^{\prime} \mathrm{W}$ & 86.4 & 9.6 & 75 \\
\hline 0706 & $36^{\circ} 57.10^{\prime} \mathrm{N}$ & $00^{\circ} \quad 24.50^{\prime} \mathrm{W}$ & 110.6 & 10.6 & 81 \\
\hline 0718 & $36^{\circ} 57.40^{\prime} \mathrm{N}$ & $27.10^{\prime} \mathrm{W}$ & 112.7 & 10.6 & 90 \\
\hline 0730 & $36^{\circ} 57.40^{\prime} \mathrm{N}$ & $29.80^{\prime} \mathrm{W}$ & 114.8 & 10.6 & 81 \\
\hline 0840 & $36^{\circ} 59.30^{\prime} \mathrm{N}$ & $45.00^{\prime} \mathrm{W}$ & 127.1 & 9.4 & 81 \\
\hline 1030 & $37^{\circ} \quad 2.00^{\prime} \mathrm{N}$ & $6.30^{\prime} \mathrm{W}$ & 144.3 & 9.5 & 81 \\
\hline 1100 & $37^{\circ} \quad 2.80^{\prime} \mathrm{N}$ & $12.10^{\prime} \mathrm{W}$ & 149.1 & 9.5 & 82 \\
\hline 1218 & $4.50^{\prime} \mathrm{N}$ & $27.40^{\prime} \mathrm{W}$ & 161.4 & 9.4 & 80 \\
\hline 1218 & $4.50^{\prime} \mathrm{N}$ & $27.40^{\prime} \mathrm{W}$ & 161.4 & 9.4 & 94 \\
\hline 1230 & $4.40^{\prime} \mathrm{N}$ & $29.70^{\prime} \mathrm{W}$ & 163.2 & 9.4 & 80 \\
\hline 1404 & $7.00^{\prime} \mathrm{N}$ & $47.90^{\prime} \mathrm{W}$ & 178.0 & 9.5 & 81 \\
\hline 1550 & $37^{\circ} \quad 9.70^{\prime} \mathrm{N}$ & $08.70^{\prime} \mathrm{W}$ & 194.8 & 9.2 & 76 \\
\hline 1620 & $37^{\circ} 10.80^{\prime} \mathrm{N}$ & $14.30^{\prime} \mathrm{W}$ & 199.4 & 9.3 & 75 \\
\hline 1622 & $37^{\circ} 10.90^{\prime} \mathrm{N}$ & $14.70^{\prime} \mathrm{W}$ & 199.7 & 10.4 & 78 \\
\hline 1640 & $37^{\circ} 11.60^{\prime} \mathrm{N}$ & $18.50^{\prime} \mathrm{W}$ & 202.8 & 10.4 & 72 \\
\hline 1740 & $37^{\circ} 14.80^{\prime} \mathrm{N}$ & $31.00^{\prime} \mathrm{W}$ & 213.3 & 9.9 & 77 \\
\hline 2012 & $37^{\circ} 20.50^{\prime} \mathrm{N}$ & $1.60^{\prime} \mathrm{W}$ & 238.3 & 9.1 & 74 \\
\hline 2138 & $37^{\circ} 24.20^{\prime} \mathrm{N}$ & $17.40^{\prime} \mathrm{W}$ & 251.4 & 9.3 & 74 \\
\hline 2328 & $37^{\circ} 28.80^{\prime} \mathrm{N}$ & $3^{\circ} \quad 38.00^{\prime} \mathrm{W}$ & 268.3 & 8.8 & 77 \\
\hline
\end{tabular}

\section{(16 April 1975)}

$\begin{array}{rr}000 & 37^{\circ} 29.90^{\prime} \mathrm{N} \\ 0116 & 37^{\circ} 32.40^{\prime} \mathrm{N} \\ 0202 & 37^{\circ} 34.60^{\prime} \mathrm{N} \\ 0350 & 37^{\circ} 39.30^{\prime} \mathrm{N} \\ 0510 & 37^{\circ} 42.90^{\prime} \mathrm{N} \\ 0540 & 37^{\circ} 44.10^{\prime} \mathrm{N} \\ 0602 & 37^{\circ} 45.20^{\prime} \mathrm{N} \\ 0618 & 37^{\circ} 44.20^{\prime} \mathrm{N} \\ 0656 & 37^{\circ} 41.60^{\prime} \mathrm{N} \\ 0720 & 37^{\circ} 40.10^{\prime} \mathrm{N} \\ 0750 & 37^{\circ} 39.00^{\prime} \mathrm{N} \\ 0752 & 37^{\circ} 38.90^{\prime} \mathrm{N} \\ 0815 & 37^{\circ} 37.60^{\prime} \mathrm{N} \\ 0854 & 37^{\circ} 35.90^{\prime} \mathrm{N} \\ 0854 & 37^{\circ} 35.90^{\prime} \mathrm{N}\end{array}$

$\begin{array}{lll}3^{\circ} & 43.70^{\prime} \mathrm{W} & 273.0 \\ 3^{\circ} & 57.40^{\prime} \mathrm{W} & 284.1 \\ 4^{\circ} & 05.30^{\prime} \mathrm{W} & 290.8 \\ 4^{\circ} & 24.70^{\prime} \mathrm{W} & 306.9 \\ 4^{\circ} & 38.30^{\prime} \mathrm{W} & 318.2 \\ 4^{\circ} & 43.60^{\prime} \mathrm{W} & 322.6 \\ 4^{\circ} & 47.70^{\prime} \mathrm{W} & 326.0 \\ 4^{\circ} & 50.50^{\prime} \mathrm{W} & 328.4 \\ 4^{\circ} & 56.70^{\prime} \mathrm{W} & 334.0 \\ 5^{\circ} & 00.80^{\prime} \mathrm{W} & 337.6 \\ 5^{\circ} & 06.30^{\prime} \mathrm{W} & 342.1 \\ 5^{\circ} & 06.60^{\prime} \mathrm{W} & 342.3 \\ 5^{\circ} & 09.80^{\prime} \mathrm{W} & 345.2 \\ 5^{\circ} & 15.60^{\prime} \mathrm{W} & 350.0 \\ 5^{\circ} & 15.60^{\prime} \mathrm{W} & 350.0\end{array}$

$\begin{array}{rr}8.8 & 77 \\ 8.7 & 71 \\ 8.9 & 73 \\ 8.5 & 72 \\ 8.7 & 74 \\ 9.3 & 71 \\ 9.1 & 114 \\ 8.8 & 118 \\ 9.0 & 115 \\ 9.0 & 104 \\ 7.2 & 115 \\ 7.5 & 117 \\ 7.5 & 110 \\ 7.8 & 108 \\ 0.0 & 0\end{array}$

(18 April 1975)

\begin{tabular}{lllllrl}
0645 & $37^{\circ} 35.90^{\prime} \mathrm{N}$ & $5^{\circ}$ & $15.60^{\prime} \mathrm{W}$ & 350.0 & 1.4 & 166 \\
0646 & $37^{\circ} 35.90^{\prime} \mathrm{N}$ & $5^{\circ}$ & $15.60^{\prime} \mathrm{W}$ & 350.1 & 3.6 & 356 \\
0700 & $37^{\circ} 36.70^{\prime} \mathrm{N}$ & $5^{\circ}$ & $15.50^{\prime} \mathrm{W}$ & 350.9 & 8.0 & 354 \\
0754 & $37^{\circ} 43.90^{\prime} \mathrm{N}$ & $5^{\circ}$ & $14.60^{\prime} \mathrm{W}$ & 358.1 & 8.6 & 348 \\
0934 & $37^{\circ} 57.90^{\prime} \mathrm{N}$ & $5^{\circ}$ & $10.80^{\prime} \mathrm{W}$ & 372.4 & 9.5 & 353 \\
1118 & $38^{\circ} 14.30^{\prime} \mathrm{N}$ & $5^{\circ}$ & $08.20^{\prime} \mathrm{W}$ & 389.0 & 9.9 & 351 \\
1310 & $38^{\circ} 32.50^{\prime} \mathrm{N}$ & $5^{\circ}$ & $04.70^{\prime} \mathrm{W}$ & 407.4 & 10.5 & 355 \\
1326 & $38^{\circ} 35.30^{\prime} \mathrm{N}$ & $5^{\circ}$ & $04.40^{\prime} \mathrm{W}$ & 410.2 & 9.6 & 355 \\
1400 & $38^{\circ} 40.70^{\prime} \mathrm{N}$ & $5^{\circ}$ & $03.70^{\prime} \mathrm{W}$ & 415.6 & 9.6 & 355 \\
1510 & $38^{\circ} 51.80^{\prime} \mathrm{N}$ & $5^{\circ} 02.40^{\prime} \mathrm{W}$ & 426.8 & 9.6 & 354 \\
1512 & $38^{\circ} 52.10^{\prime} \mathrm{N}$ & $5^{\circ} 02.40^{\prime} \mathrm{W}$ & 427.1 & 9.7 & 10 \\
1522 & $38^{\circ} 53.70^{\prime} \mathrm{N}$ & $5^{\circ} 02.70^{\prime} \mathrm{W}$ & 428.7 & 9.7 & 20 \\
1530 & $38^{\circ} 54.90^{\prime} \mathrm{N}$ & $5^{\circ} 03.30^{\prime} \mathrm{W}$ & 430.0 & 9.7 & 10 \\
1540 & $38^{\circ} 56.50^{\prime} \mathrm{N}$ & $5^{\circ} 03.60^{\prime} \mathrm{W}$ & 431.6 & 9.6 & 355 \\
1615 & $39^{\circ} 02.10^{\prime} \mathrm{N}$ & $5^{\circ} 03.10^{\prime} \mathrm{W}$ & 437.2 & 9.6 & 351 \\
1632 & $39^{\circ} 04.80^{\prime} \mathrm{N}$ & $5^{\circ} 02.50^{\prime} \mathrm{W}$ & 439.9 & 9.8 & 349 \\
\hline
\end{tabular}

TABLE 1 - Continued

\begin{tabular}{|c|c|c|c|c|c|}
\hline Time & Latitude & Longitude & $\begin{array}{c}\text { Distance } \\
\text { (miles) }\end{array}$ & $\begin{array}{c}\text { Speed } \\
\text { (knots) }\end{array}$ & $\begin{array}{c}\begin{array}{c}\text { Course } \\
\text { (degrees) }\end{array} \\
\end{array}$ \\
\hline 1700 & $39^{\circ} 09.30^{\prime} \mathrm{N}$ & $5^{\circ} \quad 01.40^{\prime} \mathrm{W}$ & 444.5 & 9.5 & 352 \\
\hline 1740 & $39^{\circ} 15.60^{\prime} \mathrm{N}$ & $5^{\circ} \quad 00.30^{\prime} \mathrm{W}$ & 450.9 & 10.3 & 350 \\
\hline 1816 & $39^{\circ} 21.70^{\prime} \mathrm{N}$ & $4^{\circ} \quad 58.90^{\prime} \mathrm{W}$ & 457.1 & 8.9 & 347 \\
\hline 1816 & $39^{\circ} 21.70^{\prime} \mathrm{N}$ & $4^{\circ} \quad 58.90^{\prime} \mathrm{W}$ & 457.1 & 8.9 & 345 \\
\hline 1926 & $39^{\circ} 31.70^{\prime} \mathrm{N}$ & $4^{\circ} \quad 55.40^{\prime} \mathrm{W}$ & 467.4 & 9.7 & 345 \\
\hline 2000 & $39^{\circ} 37.00^{\prime} \mathrm{N}$ & $4^{\circ} \quad 53.60^{\prime} \mathrm{W}$ & 472.9 & 9.6 & 348 \\
\hline 2044 & $39^{\circ} 43.90^{\prime} \mathrm{N}$ & $4^{\circ} \quad 51.70^{\prime} \mathrm{W}$ & 480.0 & 9.2 & 351 \\
\hline 2133 & $39^{\circ} 51.30^{\prime} \mathrm{N}$ & $4^{\circ} 50.10^{\prime} \mathrm{W}$ & 487.5 & 9.2 & 333 \\
\hline 2228 & $39^{\circ} 58.90^{\prime} \mathrm{N}$ & $4^{\circ} \quad 45.20^{\prime} \mathrm{W}$ & 496.0 & 10.5 & 332 \\
\hline 2249 & $40^{\circ} 02.10^{\prime} \mathrm{N}$ & $4^{\circ} \quad 42.90^{\prime} \mathrm{W}$ & 499.6 & 10.0 & 256 \\
\hline 2255 & $40^{\circ} 01.90^{\prime} \mathrm{N}$ & $4^{\circ} \quad 41.70^{\prime} \mathrm{W}$ & 500.6 & 10.5 & 332 \\
\hline 2304 & $40^{\circ} 03.30^{\prime} \mathrm{N}$ & $4^{\circ} \quad 40.70^{\prime} \mathrm{W}$ & 502.2 & 10.0 & 256 \\
\hline 2317 & $40^{\circ} 02.70^{\prime} \mathrm{N}$ & $4^{\circ} \quad 38.00^{\prime} \mathrm{W}$ & 504.3 & 8.4 & 164 \\
\hline 2329 & $40^{\circ} 01.10^{\prime} \mathrm{N}$ & $4^{\circ} \quad 38.60^{\prime} \mathrm{W}$ & 506.0 & 9.1 & 53 \\
\hline 2335 & $40^{\circ} 01.70^{\prime} \mathrm{N}$ & $4^{\circ} \quad 39.50^{\prime} \mathrm{W}$ & 506.9 & 7.3 & 52 \\
\hline \multicolumn{6}{|c|}{ (19 April 1975) } \\
\hline 0000 & $40^{\circ} 03.60^{\prime} \mathrm{N}$ & $4^{\circ} \quad 42.70^{\prime} \mathrm{W}$ & 510.0 & 7.3 & 52 \\
\hline 0002 & $40^{\circ} 03.70^{\prime} \mathrm{N}$ & $4^{\circ} \quad 42.90^{\prime} \mathrm{W}$ & 510.2 & 6.0 & 50 \\
\hline 0014 & $40^{\circ} 04.50^{\prime} \mathrm{N}$ & $4^{\circ} \quad 44.10^{\prime} \mathrm{W}$ & 511.4 & 7.2 & 62 \\
\hline 0035 & $40^{\circ} 05.70^{\prime} \mathrm{N}$ & $4^{\circ} \quad 47.00^{\prime} \mathrm{W}$ & 514.0 & 7.1 & 240 \\
\hline 0122 & $40^{\circ} 02.90^{\prime} \mathrm{N}$ & $4^{\circ} \quad 40.80^{\prime} \mathrm{W}$ & 519.5 & 6.4 & 240 \\
\hline 0126 & $40^{\circ} 02.70^{\prime} \mathrm{N}$ & $4^{\circ} \quad 40.30^{\prime} \mathrm{W}$ & 519.9 & 8.2 & 254 \\
\hline 0137 & $40^{\circ} 02.30^{\prime} \mathrm{N}$ & $4^{\circ} \quad 38.40^{\prime} \mathrm{W}$ & 521.4 & 5.8 & 169 \\
\hline 0158 & $40^{\circ} 00.30^{\prime} \mathrm{N}$ & $4^{\circ} \quad 38.90^{\prime} \mathrm{W}$ & 523.5 & 4.6 & 171 \\
\hline 0200 & $40^{\circ} 00.10^{\prime} \mathrm{N}$ & $4^{\circ} \quad 39.00^{\prime} \mathrm{W}$ & 523.6 & 5.6 & 53 \\
\hline 0310 & $40^{\circ} 04.10^{\prime} \mathrm{N}$ & $4^{\circ} \quad 45.70^{\prime} \mathrm{W}$ & 530.1 & 4.8 & 57 \\
\hline 0326 & $40^{\circ} 04.80^{\prime} \mathrm{N}$ & $4^{\circ} \quad 47.10^{\prime} \mathrm{W}$ & 531.4 & 6.2 & 70 \\
\hline 0326 & $40^{\circ} 04.80^{\prime} \mathrm{N}$ & $4^{\circ} \quad 47.10^{\prime} \mathrm{W}$ & 531.4 & 0.0 & 0 \\
\hline 0605 & $40^{\circ} 04.80^{\prime} \mathrm{N}$ & $4^{\circ} \quad 47.10^{\prime} \mathrm{W}$ & 531.4 & 1.0 & 319 \\
\hline 0605 & $40^{\circ} 04.80^{\prime} \mathrm{N}$ & $4^{\circ} \quad 47.10^{\prime} \mathrm{W}$ & 531.4 & 4.0 & 153 \\
\hline 0620 & $40^{\circ} 03.90^{\prime} \mathrm{N}$ & $4^{\circ} \quad 47.70^{\prime} \mathrm{W}$ & 532.4 & 4.1 & 171 \\
\hline 0648 & $40^{\circ} 02.00^{\prime} \mathrm{N}$ & $4^{\circ} \quad 48.10^{\prime} \mathrm{W}$ & 534.3 & 5.0 & 165 \\
\hline 0648 & $40^{\circ} 02.00^{\prime} \mathrm{N}$ & $4^{\circ} \quad 48.10^{\prime} \mathrm{W}$ & 534.3 & 0.0 & 0 \\
\hline
\end{tabular}

(25 April 1975)

\begin{tabular}{|c|c|c|c|c|c|c|}
\hline 0230 & $40^{\circ} 02.00^{\prime} \mathrm{N}$ & $4^{\circ}$ & $48.10^{\prime} \mathrm{W}$ & 534.3 & 1.6 & 313 \\
\hline 0230 & $40^{\circ} 02.00^{\prime} \mathrm{N}$ & $4^{\circ}$ & $48.10^{\prime} \mathrm{W}$ & 534.3 & 5.9 & 110 \\
\hline 0300 & $40^{\circ} 01.00^{\prime} \mathrm{N}$ & $4^{\circ}$ & $51.70^{\prime} \mathrm{W}$ & 537.3 & 8.0 & 111 \\
\hline 0400 & $39^{\circ} 58.10^{\prime} \mathrm{N}$ & $5^{\circ}$ & $01.40^{\prime} \mathrm{W}$ & 545.2 & 7.8 & 113 \\
\hline 0524 & $39^{\circ} 53.80^{\prime} \mathrm{N}$ & $5^{\circ}$ & $14.40^{\prime} \mathrm{W}$ & 556.1 & 8.5 & 120 \\
\hline 0544 & $39^{\circ} 52.40^{\prime} \mathrm{N}$ & $5^{\circ}$ & $17.60^{\prime} \mathrm{W}$ & 558.9 & 8.0 & 116 \\
\hline 0550 & $39^{\circ} 52.10^{\prime} \mathrm{N}$ & $5^{\circ}$ & $18.50^{\prime} \mathrm{W}$ & 559.7 & 8.0 & 120 \\
\hline 0714 & $39^{\circ} 46.40^{\prime} \mathrm{N}$ & $5^{\circ}$ & $31.10^{\prime} \mathrm{W}$ & 570.9 & 8.2 & 123 \\
\hline 0730 & $39^{\circ} 45.20^{\prime} \mathrm{N}$ & $5^{\circ}$ & $33.50^{\prime} \mathrm{W}$ & 573.1 & 8.2 & 120 \\
\hline 0735 & $39^{\circ} 44.90^{\prime} \mathrm{N}$ & $5^{\circ}$ & $34.30^{\prime} \mathrm{W}$ & 573.8 & 8.3 & 120 \\
\hline 0752 & $39^{\circ} 43.70^{\prime} \mathrm{N}$ & $5^{\circ}$ & $36.90^{\prime} \mathrm{W}$ & 576.1 & 8.8 & 117 \\
\hline 0900 & $39^{\circ} 39.10^{\prime} \mathrm{N}$ & $5^{\circ}$ & $48.40^{\prime} \mathrm{W}$ & 586.1 & 8.9 & 115 \\
\hline 1014 & $39^{\circ} 34.40^{\prime} \mathrm{N}$ & $6^{\circ}$ & $01.20^{\prime} \mathrm{W}$ & 597.0 & 9.5 & 119 \\
\hline 1015 & $39^{\circ} 34.30^{\prime} \mathrm{N}$ & $6^{\circ}$ & $01.40^{\prime} W$ & 597.2 & 9.5 & 116 \\
\hline 1204 & $39^{\circ} 26.70^{\prime} \mathrm{N}$ & $6^{\circ}$ & $21.40^{\prime} \mathrm{W}$ & 614.4 & 9.4 & 117 \\
\hline 1304 & $39^{\circ} 22.50^{\prime} \mathrm{N}$ & $6^{\circ}$ & $32.30^{\prime} \mathrm{W}$ & 623.8 & 9.3 & 116 \\
\hline 1400 & $39^{\circ} 18.70^{\prime} \mathrm{N}$ & $6^{\circ}$ & $42.40^{\prime} \mathrm{W}$ & 632.5 & 9.3 & 114 \\
\hline 1448 & $39^{\circ} 15.70^{\prime} \mathrm{N}$ & $6^{\circ}$ & $51.20^{\prime} \mathrm{W}$ & 639.9 & 8.8 & 114 \\
\hline 1540 & $39^{\circ} 12.60^{\prime} \mathrm{N}$ & $7^{\circ}$ & $00.20^{\prime} \mathrm{W}$ & 647.6 & 8.8 & 112 \\
\hline 1546 & $39^{\circ} 12.30^{\prime} \mathrm{N}$ & $7^{\circ}$ & $01.30^{\prime} \mathrm{W}$ & 648.5 & 8.8 & 107 \\
\hline 1634 & $39^{\circ} 10.30^{\prime} \mathrm{N}$ & $7^{\circ}$ & $10.00^{\prime} \mathrm{W}$ & 655.5 & 9.2 & 108 \\
\hline 1718 & $39^{\circ} 08.20^{\prime} \mathrm{N}$ & $7^{\circ}$ & $18.30^{\prime} \mathrm{W}$ & 662.3 & 9.2 & 107 \\
\hline 1738 & $39^{\circ} 07.30^{\prime} \mathrm{N}$ & $7^{\circ}$ & $22.10^{\prime} \mathrm{W}$ & 665.4 & 9.2 & 108 \\
\hline 1745 & $39^{\circ} 07.00^{\prime} \mathrm{N}$ & $7^{\circ}$ & $23.40^{\prime} \mathrm{W}$ & 666.4 & 9.2 & 113 \\
\hline 1904 & $39^{\circ} 02.30^{\prime} \mathrm{N}$ & $7^{\circ}$ & $37.80^{\prime} \mathrm{W}$ & 678.5 & 8.8 & 119 \\
\hline 1930 & $39^{\circ} 00.40^{\prime} \mathrm{N}$ & $7^{\circ}$ & $42.10^{\prime} \mathrm{W}$ & 682.4 & 8.9 & 121 \\
\hline 2122 & $38^{\circ} 51.90^{\prime} \mathrm{N}$ & $8^{\circ}$ & $00.30^{\prime} \mathrm{W}$ & 698.9 & 9.3 & 117 \\
\hline 2158 & $38^{\circ} 49.40^{\prime} \mathrm{N}$ & $8^{\circ}$ & $06.70^{\prime} \mathrm{W}$ & 704.5 & 8.6 & 118 \\
\hline 2200 & $38^{\circ} 49.30^{\prime} \mathrm{N}$ & $8^{\circ}$ & $07.00^{\prime} \mathrm{W}$ & 704.8 & 8.6 & 116 \\
\hline 2310 & $38^{\circ} 44.90^{\prime} \mathrm{N}$ & $8^{\circ}$ & $18.60^{\prime} \mathrm{W}$ & 714.8 & 8.9 & 116 \\
\hline 2332 & $38^{\circ} 43.50^{\prime} \mathrm{N}$ & $8^{\circ}$ & $22.40^{\prime} \mathrm{W}$ & 718.1 & 8.9 & 90 \\
\hline
\end{tabular}


TABLE 1 - Continued

\begin{tabular}{lllccc}
\hline Time & Latitude & Longitude & $\begin{array}{c}\text { Distance } \\
\text { (miles) }\end{array}$ & $\begin{array}{c}\text { Speed } \\
\text { (knots) }\end{array}$ & $\begin{array}{c}\text { Course } \\
\text { (degrees) }\end{array}$ \\
\hline
\end{tabular}

\section{(26 April 1975)}

\begin{tabular}{|c|c|c|c|c|c|c|}
\hline 000 & $38^{\circ} \quad 43.50^{\prime} \mathrm{N}$ & $8^{\circ}$ & $27.70^{\prime} \mathrm{W}$ & 722.2 & 8.9 & 90 \\
\hline 0054 & $38^{\circ} 43.50^{\prime} \mathrm{N}$ & $8^{\circ}$ & $37.90^{\prime} \mathrm{W}$ & 730.2 & 7.9 & 90 \\
\hline 0150 & $38^{\circ} 43.60^{\prime} \mathrm{N}$ & $8^{\circ}$ & $47.30^{\prime} \mathrm{W}$ & 737.5 & 7.9 & . \\
\hline 0240 & $38^{\circ} 45.80^{\prime} \mathrm{N}$ & $8^{\circ}$ & $55.30^{\prime} \mathrm{W}$ & 744.1 & 8.9 & \\
\hline 0518 & $38^{\circ} 53.70^{\prime} \mathrm{N}$ & $9^{\circ}$ & $23.70^{\prime} \mathrm{W}$ & 767.6 & 7.9 & \\
\hline 0610 & $38^{\circ} 55.90^{\prime} \mathrm{N}$ & $9^{\circ}$ & $32.10^{\prime} \mathrm{W}$ & 774.5 & 7.4 & \\
\hline 0620 & $38^{\circ} 56.30^{\prime} \mathrm{N}$ & $9^{\circ}$ & $33.60^{\prime} \mathrm{W}$ & 775.7 & 8.3 & \\
\hline 0650 & $38^{\circ} 56.80^{\prime} \mathrm{N}$ & $9^{\circ}$ & $38.90^{\prime} W$ & 779.9 & 8.3 & \\
\hline 0702 & $38^{\circ} 57.00^{\prime} \mathrm{N}$ & $9^{\circ}$ & $41.00^{\prime} \mathrm{W}$ & 781.5 & 8.2 & \\
\hline 0725 & $38^{\circ} 57.80^{\prime} \mathrm{N}$ & $9^{\circ}$ & $44.90^{\prime} \mathrm{W}$ & 784.7 & 5.8 & \\
\hline 0738 & $38^{\circ} 58.10^{\prime} \mathrm{N}$ & $9^{\circ}$ & $46.50^{\prime} \mathrm{W}$ & 786.0 & 6.7 & 158 \\
\hline 0745 & $38^{\circ} 57.40^{\prime} \mathrm{N}$ & $9^{\circ}$ & $46.90^{\prime} \mathrm{W}$ & 786.7 & 8.2 & \\
\hline 0918 & $39^{\circ} 00.70^{\prime} \mathrm{N}$ & $10^{\circ}$ & $02.70^{\prime} \mathrm{W}$ & 799.5 & 7.5 & \\
\hline 0930 & $39^{\circ} 01.10^{\prime} \mathrm{N}$ & $10^{\circ}$ & $04.60^{\prime} \mathrm{W}$ & 801.0 & 7.8 & \\
\hline 0940 & $39^{\circ} 01.40^{\prime} \mathrm{N}$ & $10^{\circ}$ & $06.20^{\prime} \mathrm{W}$ & 802.3 & 7.8 & \\
\hline 0956 & $39^{\circ} 02.10^{\prime} \mathrm{N}$ & $10^{\circ}$ & $08.70^{\prime} W$ & 804.3 & 7.8 & \\
\hline 1030 & $39^{\circ} 03.60^{\prime} \mathrm{N}$ & $10^{\circ}$ & $14.00^{\prime} \mathrm{W}$ & 808.7 & 8.0 & \\
\hline 1100 & $39^{\circ} 04.90^{\prime} \mathrm{N}$ & $10^{\circ}$ & $18.80^{\prime} \mathrm{W}$ & 812.7 & 7.0 & \\
\hline 1104 & $39^{\circ} 05.10^{\prime} \mathrm{N}$ & $10^{\circ}$ & $19.40^{\prime} \mathrm{W}$ & 813.2 & 7.3 & \\
\hline 1216 & $39^{\circ} 08.20^{\prime} \mathrm{N}$ & $10^{\circ}$ & $30.00^{\prime} \mathrm{W}$ & 822.0 & 7.3 & \\
\hline 1356 & $39^{\circ} 12.40^{\prime} \mathrm{N}$ & $10^{\circ}$ & $44.80^{\prime} \mathrm{W}$ & 834.2 & 8.1 & \\
\hline 1358 & $39^{\circ} 12.50^{\prime} \mathrm{N}$ & $10^{\circ}$ & $45.10^{\prime} \mathrm{W}$ & 834.4 & 7.7 & 67 \\
\hline 1442 & $39^{\circ} 14.70^{\prime} \mathrm{N}$ & $10^{\circ}$ & $51.80^{\prime} \mathrm{W}$ & 840.1 & 7.7 & \\
\hline 1546 & $39^{\circ} 17.90^{\prime} \mathrm{N}$ & $11^{\circ}$ & $01.60^{\prime} \mathrm{W}$ & 848.3 & 8.0 & \\
\hline 1624 & $39^{\circ} 19.60^{\prime} \mathrm{N}$ & $11^{\circ}$ & $07.80^{\prime} \mathrm{W}$ & 853.4 & 7.6 & \\
\hline 1640 & $39^{\circ} 20.40^{\prime} \mathrm{N}$ & $11^{\circ}$ & $10.20^{\prime} \mathrm{W}$ & 855.4 & 7.8 & \\
\hline 1734 & $39^{\circ} 23.10^{\prime} \mathrm{N}$ & $11^{\circ}$ & $18.60^{\prime} \mathrm{W}$ & 862.5 & 8.2 & \\
\hline 1810 & $39^{\circ} 25.00^{\prime} \mathrm{N}$ & $11^{\circ}$ & $24.50^{\prime} \mathrm{W}$ & 867.4 & 8.1 & \\
\hline 1918 & $39^{\circ} 28.70^{\prime} \mathrm{N}$ & $11^{\circ}$ & $35.30^{\prime} \mathrm{W}$ & 876.5 & 8.4 & \\
\hline 2004 & $39^{\circ} 31.30^{\prime} \mathrm{N}$ & $11^{\circ}$ & $42.90^{\prime} \mathrm{W}$ & 882.9 & 8.3 & \\
\hline 2020 & $39^{\circ} 32.10^{\prime} \mathrm{N}$ & $11^{\circ}$ & $45.60^{\prime} \mathrm{W}$ & 885.1 & 8.3 & \\
\hline 2028 & $39^{\circ} 32.50^{\prime} \mathrm{N}$ & $11^{\circ}$ & $46.90^{\prime} \mathrm{W}$ & 886.2 & 8.8 & \\
\hline 2106 & $39^{\circ} 34.60^{\prime} \mathrm{N}$ & $11^{\circ}$ & $53.60^{\prime} \mathrm{W}$ & 891.8 & 8.8 & \\
\hline 2214 & $39^{\circ} 37.90^{\prime} \mathrm{N}$ & $12^{\circ}$ & $05.80^{\prime} \mathrm{W}$ & 901.8 & 7.9 & \\
\hline
\end{tabular}

\section{(27 April 1975)}

\begin{tabular}{|c|c|c|c|c|c|c|}
\hline 000 & $39^{\circ} 42.50^{\prime} \mathrm{N}$ & $12^{\circ}$ & $22.90^{\prime} \mathrm{WV}$ & 915.7 & 7.9 & 71 \\
\hline 0002 & $39^{\circ} 42.60^{\prime} \mathrm{N}$ & $12^{\circ}$ & $23.20^{\prime} \mathrm{W}$ & 916.0 & 7.5 & 67 \\
\hline 0020 & $39^{\circ} 43.50^{\prime} \mathrm{N}$ & $12^{\circ}$ & $25.90^{\prime} \mathrm{W}$ & 918.2 & 7.7 & 71 \\
\hline 0045 & $39^{\circ} 44.50^{\prime} \mathrm{N}$ & $12^{\circ}$ & $29.80^{\prime} \mathrm{W}$ & 921.4 & 7.7 & 74 \\
\hline 0200 & $39^{\circ} 47.20^{\prime} \mathrm{N}$ & $12^{\circ}$ & $41.80^{\prime} \mathrm{W}$ & 931.0 & 7.7 & 67 \\
\hline 0228 & $39^{\circ} 48.60^{\prime} \mathrm{N}$ & $12^{\circ}$ & $46.10^{\prime} \mathrm{W}$ & 934.6 & 7.8 & 121 \\
\hline 0242 & $39^{\circ} 47.60^{\prime} \mathrm{N}$ & $12^{\circ}$ & $48.10^{\prime} \mathrm{W}$ & 936.4 & 7.7 & 118 \\
\hline 0320 & $39^{\circ} 45.40^{\prime} \mathrm{N}$ & $12^{\circ}$ & $53.70^{\prime} \mathrm{W}$ & 941.3 & 6.1 & 117 \\
\hline 0345 & $39^{\circ} 44.20^{\prime} \mathrm{N}$ & $12^{\circ}$ & $56.70^{\prime} \mathrm{W}$ & 943.8 & 6.0 & 110 \\
\hline 0346 & $39^{\circ} 44.20^{\prime} \mathrm{N}$ & $12^{\circ}$ & $56.80^{\prime} \mathrm{W}$ & 943.9 & 5.6 & 110 \\
\hline 0348 & $39^{\circ} 44.10^{\prime} \mathrm{N}$ & $12^{\circ}$ & $57.00^{\prime} \mathrm{W}$ & 944.1 & 5.5 & 102 \\
\hline 0410 & $39^{\circ} 43.70^{\prime} \mathrm{N}$ & $12^{\circ}$ & $59.60^{\prime} \mathrm{W}$ & 946.1 & 8.0 & 100 \\
\hline 0410 & $39^{\circ} 43.70^{\prime} \mathrm{N}$ & $12^{\circ}$ & $59.60^{\prime} \mathrm{W}$ & 946.1 & 0.0 & 0 \\
\hline \multicolumn{7}{|c|}{ (29 April 1975) } \\
\hline 0730 & $39^{\circ} 43.70^{\prime} \mathrm{N}$ & $12^{\circ}$ & $59.60^{\prime} \mathrm{W}$ & 946.1 & 0.4 & 292 \\
\hline 0730 & $39^{\circ} 43.70^{\prime} \mathrm{N}$ & $12^{\circ}$ & $59.60^{\prime} \mathrm{W}$ & 946.1 & 4.9 & 126 \\
\hline 0755 & $39^{\circ} 42.50^{\prime} \mathrm{N}$ & $13^{\circ}$ & $01.70^{\prime} \mathrm{W}$ & 948.2 & 9.0 & 126 \\
\hline 0845 & $39^{\circ} 38.10^{\prime} \mathrm{N}$ & $13^{\circ}$ & $09.60^{\prime} \mathrm{W}$ & 955.7 & 9.0 & 120 \\
\hline 0908 & $39^{\circ} 36.40^{\prime} \mathrm{N}$ & $13^{\circ}$ & $13.50^{\prime} \mathrm{W}$ & 959.1 & 8.5 & 122 \\
\hline 1006 & $39^{\circ} 32.00^{\prime} \mathrm{N}$ & $13^{\circ}$ & $22.50^{\prime} \mathrm{W}$ & 967.3 & 8.5 & 120 \\
\hline 1138 & $39^{\circ} 25.40^{\prime} \mathrm{N}$ & $13^{\circ}$ & $37.10^{\prime} \mathrm{W}$ & 980.4 & 8.3 & 120 \\
\hline 1158 & $39^{\circ} 24.00^{\prime} \mathrm{N}$ & $13^{\circ}$ & $40.20^{\prime} \mathrm{W}$ & 983.1 & 8.2 & 121 \\
\hline 1318 & $39^{\circ} 18.40^{\prime} \mathrm{N}$ & $13^{\circ}$ & $52.40^{\prime} \mathrm{W}$ & 994.1 & 8.5 & 122 \\
\hline 1410 & $39^{\circ} 14.50^{\prime} \mathrm{N}$ & $14^{\circ}$ & $00.50^{\prime} \mathrm{W}$ & 1001.5 & 8.7 & 122 \\
\hline 1450 & $39^{\circ} 11.50^{\prime} \mathrm{N}$ & $14^{\circ}$ & $06.90^{\prime} \mathrm{W}$ & 1007.3 & 8.7 & 121 \\
\hline 1540 & $39^{\circ} 07.80^{\prime} \mathrm{N}$ & $14^{\circ}$ & $14.90^{\prime} \mathrm{W}$ & 1014.6 & 8.7 & 118 \\
\hline 1550 & $39^{\circ} 07.10^{\prime} \mathrm{N}$ & $14^{\circ}$ & $16.60^{\prime} \mathrm{W}$ & 1016.0 & 9.1 & 116 \\
\hline 1634 & $39^{\circ} 04.20^{\prime} \mathrm{N}$ & $14^{\circ}$ & $24.30^{\prime} \mathrm{W}$ & 1022.7 & 8.2 & 118 \\
\hline
\end{tabular}

TABLE 1 - Continued

\begin{tabular}{|c|c|c|c|c|c|c|}
\hline Time & Latitude & & ngitude & $\begin{array}{c}\text { Distance } \\
\text { (miles) }\end{array}$ & $\begin{array}{c}\text { Speed } \\
\text { (knots) }\end{array}$ & $\begin{array}{c}\text { Course } \\
\text { (degrees) }\end{array}$ \\
\hline 1654 & $39^{\circ} 02.90^{\prime} \mathrm{N}$ & $14^{\circ}$ & $27.40^{\prime} \mathrm{W}$ & 1025.4 & 9.0 & 116 \\
\hline 1736 & $39^{\circ} 00.10^{\prime} \mathrm{N}$ & $14^{\circ}$ & $34.70^{\prime} \mathrm{W}$ & 1031.7 & 9.0 & 117 \\
\hline 1800 & $38^{\circ} 58.50^{\prime} \mathrm{N}$ & $14^{\circ}$ & $38.80^{\prime} \mathrm{W}$ & 1035.3 & 9.0 & 120 \\
\hline 1822 & $38^{\circ} 56.80^{\prime} \mathrm{N}$ & $14^{\circ}$ & $42.50^{\prime} \mathrm{W}$ & 1038.6 & 8.5 & 119 \\
\hline 1924 & $38^{\circ} 52.50^{\prime} \mathrm{N}$ & $14^{\circ}$ & $52.30^{\prime} \mathrm{W}$ & 1047.4 & 8.9 & 122 \\
\hline 2018 & $38^{\circ} 48.30^{\prime} \mathrm{N}$ & $15^{\circ}$ & $01.10^{\prime} \mathrm{W}$ & 1055.4 & 9.1 & 119 \\
\hline 2044 & $38^{\circ} 46.40^{\prime} \mathrm{N}$ & $15^{\circ}$ & $05.50^{\prime} \mathrm{W}$ & 105 & 9.1 & 134 \\
\hline 2114 & $38^{\circ} 43.20^{\prime} \mathrm{N}$ & $15^{\circ}$ & $09.70^{\prime} \mathrm{W}$ & 1063.9 & 9.2 & 135 \\
\hline 2241 & $38^{\circ} 33.80^{\prime} \mathrm{N}$ & $15^{\circ}$ & $21.90^{\prime} \mathrm{W}$ & 1077.3 & 9.2 & 141 \\
\hline 2302 & $38^{\circ} 31.30^{\prime} \mathrm{N}$ & $15^{\circ}$ & $24.50^{\prime} \mathrm{W}$ & 2080.5 & 9.6 & 141 \\
\hline 2305 & $38^{\circ} 30.90^{\prime} \mathrm{N}$ & $15^{\circ}$ & $24.90^{\prime} \mathrm{W}$ & 1081.0 & 9.5 & 130 \\
\hline 2320 & $38^{\circ} 29.40^{\prime} \mathrm{N}$ & $15^{\circ}$ & $27.20^{\prime} \mathrm{W}$ & 1083 & 4.9 & 131 \\
\hline 2340 & $38^{\circ} 28.30^{\prime} \mathrm{N}$ & $15^{\circ}$ & $28.80^{\prime} \mathrm{W}$ & 1085.0 & 4.6 & 167 \\
\hline 2345 & $38^{\circ} 27.90^{\prime} \mathrm{N}$ & $15^{\circ}$ & $28.90^{\prime} \mathrm{W}$ & 1085.4 & 4.6 & 167 \\
\hline
\end{tabular}

(30 April 1975)

\begin{tabular}{|c|c|c|c|c|c|c|}
\hline & & & & & & \\
\hline 0715 & $37^{\circ} 54.00^{\prime} \mathrm{N}$ & $15^{\circ}$ & $38.70^{\prime} \mathrm{W}$ & 1120.2 & 6.3 & 162 \\
\hline 0722 & $37^{\circ} 53.30^{\prime} \mathrm{N}$ & $15^{\circ}$ & $39.00^{\prime} \mathrm{W}$ & 1120.9 & 6.4 & 129 \\
\hline 0745 & $37^{\circ} 51.80^{\prime} \mathrm{N}$ & $15^{\circ}$ & $41.40^{\prime} \mathrm{W}$ & 1123.4 & 8.8 & 131 \\
\hline 0800 & $37^{\circ} 50.30^{\prime} \mathrm{N}$ & $15^{\circ}$ & $43.50^{\prime} \mathrm{W}$ & 1125.6 & 9.3 & 131 \\
\hline 0814 & $37^{\circ} 48.90^{\prime} \mathrm{N}$ & $15^{\circ}$ & $45.60^{\prime} \mathrm{W}$ & 1127.8 & 8.4 & 136 \\
\hline 0910 & $37^{\circ} 43.30^{\prime} \mathrm{N}$ & $15^{\circ}$ & $52.50^{\prime} \mathrm{W}$ & 1135.6 & 8.9 & 134 \\
\hline 1030 & $37^{\circ} 35.10^{\prime} \mathrm{N}$ & $16^{\circ}$ & $03.30^{\prime} \mathrm{W}$ & 1147.4 & 8.9 & 136 \\
\hline 1232 & $37^{\circ} 22.10^{\prime} \mathrm{N}$ & $16^{\circ}$ & $19.10^{\prime} \mathrm{W}$ & 1165.5 & 8.9 & 137 \\
\hline 1348 & $37^{\circ} 13.90^{\prime} \mathrm{N}$ & $16^{\circ}$ & $28.80^{\prime} \mathrm{W}$ & 1176.7 & 8.7 & 138 \\
\hline 1416 & $37^{\circ} 10.90^{\prime} \mathrm{N}$ & $16^{\circ}$ & $32.20^{\prime} \mathrm{W}$ & 1180.8 & 9.0 & 137 \\
\hline 1526 & $37^{\circ} 03.20^{\prime} \mathrm{N}$ & $16^{\circ}$ & $41.20^{\prime} \mathrm{W}$ & 1191.3 & 9.1 & 137 \\
\hline 1604 & $36^{\circ} 59.00^{\prime} \mathrm{N}$ & $16^{\circ}$ & $46.10^{\prime} \mathrm{W}$ & 1197.1 & 9.1 & 137 \\
\hline 1648 & $36^{\circ} 54.10^{\prime} \mathrm{N}$ & $16^{\circ}$ & $51.80^{\prime} \mathrm{W}$ & 1203.7 & 9.3 & 137 \\
\hline 1700 & $36^{\circ} 52.80^{\prime} \mathrm{N}$ & $16^{\circ}$ & $53.40^{\prime} \mathrm{W}$ & 1205.6 & 9.3 & 132 \\
\hline 1712 & $36^{\circ} 51.50^{\prime} \mathrm{N}$ & $16^{\circ}$ & $55.10^{\prime} \mathrm{W}$ & 1207.4 & 9.3 & 136 \\
\hline 1740 & $36^{\circ} 48.40^{\prime} \mathrm{N}$ & $16^{\circ}$ & $58.90^{\prime} \mathrm{W}$ & 1211.8 & 9.2 & 135 \\
\hline 1834 & $36^{\circ} 42.60^{\prime} \mathrm{N}$ & $17^{\circ}$ & $06.20^{\prime} \mathrm{W}$ & 1220.0 & 9.2 & 134 \\
\hline 1926 & $36^{\circ} 37.10^{\prime} \mathrm{N}$ & $17^{\circ}$ & $13.40^{\prime} \mathrm{W}$ & 1228.0 & 9.4 & 131 \\
\hline 2022 & $36^{\circ} 31.30^{\prime} \mathrm{N}$ & $17^{\circ}$ & $21.60^{\prime} \mathrm{W}$ & 1236.8 & 9.3 & 132 \\
\hline 2206 & $36^{\circ} 20.60^{\prime} \mathrm{N}$ & $17^{\circ}$ & $36.50^{\prime} \mathrm{W}$ & 1252.8 & 9.3 & 134 \\
\hline \multicolumn{7}{|c|}{ (1 May 1975) } \\
\hline 000 & $36^{\circ} 08.40^{\prime} \mathrm{N}$ & $17^{\circ}$ & $52.20^{\prime} \mathrm{W}$ & 1270.5 & 9.3 & 13 \\
\hline 0100 & $36^{\circ} 02.00^{\prime} \mathrm{N}$ & $18^{\circ}$ & $00.50^{\prime} \mathrm{W}$ & 1279.7 & 9.3 & 124 \\
\hline 0136 & $35^{\circ} 58.90^{\prime} \mathrm{N}$ & $18^{\circ}$ & $06.20^{\prime} \mathrm{W}$ & 1285.3 & 9.4 & 157 \\
\hline 0145 & $35^{\circ} 57.60^{\prime} \mathrm{N}$ & $18^{\circ}$ & $06.90^{\prime} \mathrm{W}$ & 1286.7 & 9.3 & 156 \\
\hline 0205 & $35^{\circ} 54.80^{\prime} \mathrm{N}$ & $18^{\circ}$ & $08.50^{\prime} \mathrm{W}$ & 1289.8 & 6.3 & 147 \\
\hline 0216 & $35^{\circ} 53.80^{\prime} \mathrm{N}$ & $18^{\circ}$ & $09.30^{\prime} \mathrm{W}$ & 1291.0 & 7.9 & 146 \\
\hline 0240 & $35^{\circ} 51.20^{\prime} \mathrm{N}$ & $18^{\circ}$ & $11.50^{\prime} \mathrm{W}$ & 1294.1 & 7.9 & 141 \\
\hline 0244 & $35^{\circ} 50.80^{\prime} \mathrm{N}$ & $18^{\circ}$ & $11.90^{\prime} \mathrm{W}$ & 1294.6 & 6.6 & 140 \\
\hline 0244 & $35^{\circ} 50.80^{\prime} \mathrm{N}$ & $18^{\circ}$ & $11.90^{\prime} \mathrm{W}$ & 1294.6 & 0.0 & \\
\hline
\end{tabular}

(4 May 1975)

\begin{tabular}{lllllrr}
0700 & $35^{\circ} 50.80^{\prime} \mathrm{N}$ & $18^{\circ}$ & $11.90^{\prime} \mathrm{W}$ & 1294.6 & 0.3 & 91 \\
0700 & $35^{\circ} 50.80^{\prime} \mathrm{N}$ & $18^{\circ}$ & $11.90^{\prime} \mathrm{W}$ & 1294.6 & 7.0 & 99 \\
0755 & $35^{\circ} 49.80^{\prime} \mathrm{N}$ & $18^{\circ}$ & $19.70^{\prime} \mathrm{W}$ & 1301.0 & 10.0 & 99 \\
0824 & $35^{\circ} 49.10^{\prime} \mathrm{N}$ & $18^{\circ}$ & $25.60^{\prime} \mathrm{W}$ & 1305.9 & 9.9 & 101 \\
0902 & $35^{\circ} 47.90^{\prime} \mathrm{N}$ & $18^{\circ}$ & $33.20^{\prime} \mathrm{W}$ & 1312.1 & 9.1 & 102 \\
1050 & $35^{\circ} 44.60^{\prime} \mathrm{N}$ & $18^{\circ}$ & $53.00^{\prime} \mathrm{W}$ & 1328.5 & 9.5 & 103 \\
1110 & $35^{\circ} 43.90^{\prime} \mathrm{N}$ & $18^{\circ}$ & $56.80^{\prime} \mathrm{W}$ & 1331.7 & 9.4 & 100 \\
1145 & $35^{\circ} 43.00^{\prime} \mathrm{N}$ & $19^{\circ}$ & $03.50^{\prime} \mathrm{W}$ & 1337.2 & 9.4 & 98 \\
1432 & $35^{\circ} 39.50^{\prime} \mathrm{N}$ & $19^{\circ}$ & $35.40^{\prime} \mathrm{W}$ & 1363.4 & 9.2 & 98 \\
1520 & $35^{\circ} 38.50^{\prime} \mathrm{N}$ & $19^{\circ}$ & $44.40^{\prime} \mathrm{W}$ & 1370.8 & 9.2 & 98 \\
1614 & $35^{\circ} 37.40^{\prime} \mathrm{N}$ & $19^{\circ}$ & $54.50^{\prime} \mathrm{W}$ & 1379.0 & 9.0 & 99 \\
1706 & $35^{\circ} 36.20^{\prime} \mathrm{N}$ & $20^{\circ}$ & $04.00^{\prime} \mathrm{W}$ & 1386.9 & 9.6 & 99 \\
1746 & $35^{\circ} 35.20^{\prime} \mathrm{N}$ & $20^{\circ}$ & $11.80^{\prime} \mathrm{W}$ & 1393.3 & 9.3 & 99 \\
1854 & $35^{\circ} 33.50^{\prime} \mathrm{N}$ & $20^{\circ}$ & $24.60^{\prime} \mathrm{W}$ & 1403.8 & 8.9 & 98 \\
1934 & $35^{\circ} 32.70^{\prime} \mathrm{N}$ & $20^{\circ}$ & $31.80^{\prime} \mathrm{W}$ & 1409.7 & 9.2 & 95 \\
2005 & $35^{\circ} 32.30^{\prime} \mathrm{N}$ & $20^{\circ}$ & $37.60^{\prime} \mathrm{W}$ & 1414.5 & 9.1 & 119 \\
2014 & $35^{\circ} 31.60^{\prime} \mathrm{N}$ & $20^{\circ}$ & $39.10^{\prime} \mathrm{W}$ & 1415.9 & 8.9 & 122 \\
\hline
\end{tabular}


TABLE 1 - Continued

\begin{tabular}{ccccccc}
\hline Time & Latitude & Longitude & $\begin{array}{c}\text { Distance } \\
\text { (miles) }\end{array}$ & $\begin{array}{c}\text { Speed } \\
\text { (knots) }\end{array}$ & $\begin{array}{c}\text { Course } \\
\text { (degrees) }\end{array}$ \\
\hline 2017 & $35^{\circ} 31.40^{\prime} \mathrm{N}$ & $20^{\circ}$ & $39.60^{\prime} \mathrm{W}$ & 1416.3 & 8.8 & 97 \\
2200 & $35^{\circ} 29.50^{\prime} \mathrm{N}$ & $20^{\circ}$ & $58.00^{\prime} \mathrm{W}$ & 1431.4 & 8.7 & 96 \\
2308 & $35^{\circ} 28.40^{\prime} \mathrm{N}$ & $21^{\circ}$ & $10.10^{\prime} \mathrm{W}$ & 1441.4 & 8.4 & 97
\end{tabular}

\section{(5 May 1975)}

$\begin{array}{rlllllr}00 & 35^{\circ} 27.50^{\prime} \mathrm{N} & 21^{\circ} & 18.90^{\prime} \mathrm{W} & 1448.6 & 8.4 & 99 \\ 0138 & 35^{\circ} 25.30^{\prime} \mathrm{N} & 21^{\circ} & 35.50^{\prime} \mathrm{W} & 1462.3 & 8.4 & 102 \\ 0250 & 35^{\circ} 23.20^{\prime} \mathrm{N} & 21^{\circ} & 47.60^{\prime} \mathrm{W} & 1472.4 & 8.1 & 102 \\ 0320 & 35^{\circ} 22.40^{\prime} \mathrm{N} & 21^{\circ} & 52.50^{\prime} \mathrm{W} & 1476.4 & 8.3 & 100 \\ 0400 & 35^{\circ} 21.40^{\prime} \mathrm{N} & 21^{\circ} & 59.20^{\prime} \mathrm{W} & 1482.0 & 8.6 & 100 \\ 0535 & 35^{\circ} 19.10^{\prime} \mathrm{N} & 22^{\circ} & 15.70^{\prime} \mathrm{W} & 1495.6 & 8.3 & 100 \\ 0544 & 35^{\circ} 18.90^{\prime} \mathrm{N} & 22^{\circ} & 17.20^{\prime} \mathrm{W} & 1496.9 & 8.3 & 96 \\ 0652 & 35^{\circ} 17.90^{\prime} \mathrm{N} & 22^{\circ} & 28.60^{\prime} \mathrm{W} & 1506.2 & 8.1 & 104 \\ 0730 & 35^{\circ} 16.70^{\prime} \mathrm{N} & 22^{\circ} & 34.70^{\prime} \mathrm{W} & 1511.4 & 8.7 & 101 \\ 0808 & 35^{\circ} 15.70^{\prime} \mathrm{N} & 22^{\circ} & 41.30^{\prime} \mathrm{W} & 1516.8 & 8.4 & 98 \\ 0928 & 35^{\circ} 14.10^{\prime} \mathrm{N} & 22^{\circ} & 54.90^{\prime} \mathrm{W} & 1528.1 & 8.7 & 98 \\ 0954 & 35^{\circ} 13.60^{\prime} \mathrm{N} & 22^{\circ} & 59.50^{\prime} \mathrm{W} & 1531.9 & 9.4 & 99 \\ 1022 & 35^{\circ} 12.90^{\prime} \mathrm{N} & 23^{\circ} & 04.80^{\prime} \mathrm{W} & 1536.2 & 9.0 & 98 \\ 1235 & 35^{\circ} 10.20^{\prime} \mathrm{N} & 23^{\circ} & 28.90^{\prime} \mathrm{W} & 1556.1 & 8.9 & 110 \\ 1326 & 35^{\circ} 07.70^{\prime} \mathrm{N} & 23^{\circ} & 37.70^{\prime} \mathrm{W} & 1563.7 & 8.9 & 111 \\ 1508 & 35^{\circ} 02.30^{\prime} \mathrm{N} & 23^{\circ} & 54.90^{\prime} \mathrm{W} & 1578.8 & 9.2 & 110 \\ 1543 & 35^{\circ} 00.50^{\prime} \mathrm{N} & 24^{\circ} & 01.00^{\prime} \mathrm{W} & 1584.2 & 9.2 & 106 \\ 1618 & 34^{\circ} 59.00^{\prime} \mathrm{N} & 24^{\circ} & 07.30^{\prime} \mathrm{W} & 1589.5 & 9.1 & 107 \\ 1656 & 34^{\circ} 57.30^{\prime} \mathrm{N} & 24^{\circ} & 14.00^{\prime} \mathrm{W} & 1595.3 & 9.1 & 106 \\ 1804 & 34^{\circ} 54.50^{\prime} \mathrm{N} & 24^{\circ} & 26.10^{\prime} \mathrm{W} & 1605.6 & 9.2 & 107 \\ 1842 & 34^{\circ} 52.80^{\prime} \mathrm{N} & 24^{\circ} & 32.90^{\prime} \mathrm{W} & 1611.4 & 8.8 & 110 \\ 1920 & 34^{\circ} 50.90^{\prime} \mathrm{N} & 24^{\circ} & 39.30^{\prime} \mathrm{W} & 1617.0 & 9.4 & 107 \\ 1945 & 34^{\circ} 49.70^{\prime} \mathrm{N} & 24^{\circ} & 43.90^{\prime} \mathrm{W} & 1620.9 & 9.4 & 94 \\ 2106 & 34^{\circ} 49.90^{\prime} \mathrm{N} & 24^{\circ} & 59.20^{\prime} \mathrm{W} & 1633.5 & 9.3 & 94 \\ 2220 & 34^{\circ} 48.10^{\prime} \mathrm{N} & 25^{\circ} & 13.10^{\prime} \mathrm{W} & 1645.0 & 8.8 & 93\end{array}$

\section{(6 May 1975)}

$\begin{aligned} 000 & 34^{\circ} 47.30^{\prime} \mathrm{N} \\ 0216 & 34^{\circ} 46.30^{\prime} \mathrm{N} \\ 0330 & 34^{\circ} 45.40^{\prime} \mathrm{N} \\ 0400 & 34^{\circ} 44.90^{\prime} \mathrm{N} \\ 0420 & 34^{\circ} 44.70^{\prime} \mathrm{N} \\ 0452 & 34^{\circ} 44.30^{\prime} \mathrm{N} \\ 0602 & 34^{\circ} 43.70^{\prime} \mathrm{N} \\ 0623 & 34^{\circ} 43.50^{\prime} \mathrm{N} \\ 0630 & 34^{\circ} 43.50^{\prime} \mathrm{N} \\ 0638 & 34^{\circ} 43.40^{\prime} \mathrm{N} \\ 0858 & 34^{\circ} 41.80^{\prime} \mathrm{N} \\ 1050 & 34^{\circ} 40.60^{\prime} \mathrm{N} \\ 1124 & 34^{\circ} 40.60^{\prime} \mathrm{N} \\ 1256 & 34^{\circ} 39.90^{\prime} \mathrm{N} \\ 1442 & 34^{\circ} 39.80^{\prime} \mathrm{N} \\ 1528 & 34^{\circ} 39.30^{\prime} \mathrm{N} \\ 1548 & 34^{\circ} 39.00^{\prime} \mathrm{N} \\ 1608 & 34^{\circ} 38.70^{\prime} \mathrm{N} \\ 1750 & 34^{\circ} 37.00^{\prime} \mathrm{N} \\ 1940 & 34^{\circ} 35.90^{\prime} \mathrm{N} \\ 2010 & 34^{\circ} 35.80^{\prime} \mathrm{N} \\ 2030 & 34^{\circ} 35.70^{\prime} \mathrm{N} \\ 2040 & 34^{\circ} 35.50^{\prime} \mathrm{N} \\ 2055 & 34^{\circ} 34.20^{\prime} \mathrm{N} \\ 2156 & 34^{\circ} 34.30^{\prime} \mathrm{N} \\ 2245 & 34^{\circ} 34.10^{\prime} \mathrm{N} \\ 2318 & 34^{\circ} 34.20^{\prime} \mathrm{N}\end{aligned}$

\begin{tabular}{|c|c|c|c|c|}
\hline $25^{\circ}$ & $30.90^{\prime} \mathrm{W}$ & 1659.6 & 8.8 & 93 \\
\hline $25^{\circ}$ & $55.20^{\prime} \mathrm{W}$ & 1679.6 & 8.6 & 95 \\
\hline $26^{\circ}$ & $08.10^{\prime} W$ & 1690.2 & 9.1 & 96 \\
\hline $26^{\circ}$ & $13.60^{\prime} \mathrm{W}$ & 1694.8 & 8.4 & 94 \\
\hline $26^{\circ}$ & $17.00^{\prime} \mathrm{W}$ & 1697.6 & 8.8 & 95 \\
\hline $26^{\circ}$ & $22.70^{\prime} \mathrm{W}$ & 1702.3 & 8.7 & 93 \\
\hline $26^{\circ}$ & $35.10^{\prime} \mathrm{W}$ & 1712.5 & 9.1 & 93 \\
\hline $26^{\circ}$ & $39.00^{\prime} \mathrm{W}$ & 1715.7 & 4.4 & 94 \\
\hline $26^{\circ}$ & $39.60^{\prime} \mathrm{W}$ & 1716.2 & 9.1 & 93 \\
\hline $26^{\circ}$ & $41.10^{\prime} \mathrm{W}$ & 1717.4 & 8.5 & 95 \\
\hline $27^{\circ}$ & $05.10^{\prime} \mathrm{W}$ & 1737.2 & 9.1 & 94 \\
\hline $27^{\circ}$ & $25.80^{\prime} \mathrm{W}$ & 1754.3 & 9.0 & 90 \\
\hline $27^{\circ}$ & $32.00^{\prime} \mathrm{W}$ & 1759.4 & 9.8 & 93 \\
\hline $27^{\circ}$ & $50.20^{\prime} \mathrm{W}$ & 1774.4 & 9.0 & 90 \\
\hline $28^{\circ}$ & $09.60^{\prime} \mathrm{W}$ & 1790.3 & 8.9 & 94 \\
\hline $28^{\circ}$ & $17.90^{\prime} \mathrm{W}$ & 1797.2 & 9.2 & 96 \\
\hline $28^{\circ}$ & $21.60^{\prime} \mathrm{W}$ & 1800.2 & 8.9 & 96 \\
\hline $28^{\circ}$ & $25.20^{\prime} \mathrm{W}$ & 1803.2 & 8.6 & 97 \\
\hline $28^{\circ}$ & $42.80^{\prime} \mathrm{W}$ & 1817.8 & 9.4 & 94 \\
\hline $29^{\circ}$ & $03.80^{\prime} \mathrm{W}$ & 1835.1 & 8.7 & 91 \\
\hline $29^{\circ}$ & $09.10^{\prime} \mathrm{W}$ & 1839.5 & 9.1 & 91 \\
\hline $29^{\circ}$ & $12.80^{\prime} \mathrm{W}$ & 1842.5 & 9.0 & 99 \\
\hline $29^{\circ}$ & $14.60^{\prime} \mathrm{W}$ & 1844.0 & 9.0 & 126 \\
\hline $29^{\circ}$ & $16.80^{\prime} \mathrm{W}$ & 1846.2 & 9.1 & 89 \\
\hline $29^{\circ}$ & $28.00^{\prime} \mathrm{W}$ & 1855.5 & 9.0 & 91 \\
\hline $29^{\circ}$ & $37.00^{\prime} \mathrm{W}$ & 1862.8 & 9.0 & 89 \\
\hline $29^{\circ}$ & $43.00^{\prime} \mathrm{W}$ & 1867.8 & 9.4 & 90 \\
\hline \multicolumn{5}{|c|}{ (7 May 1975) } \\
\hline $29^{\circ}$ & $51.00^{\prime} \mathrm{W}$ & 1874.4 & 9.4 & 90 \\
\hline $30^{\circ}$ & $00.80^{\prime} W$ & 1882.5 & 9.4 & 92 \\
\hline $30^{\circ}$ & $04.60^{\prime} \mathrm{W}$ & 1885.6 & 8.8 & 90 \\
\hline $30^{\circ}$ & $28.50^{\prime} \mathrm{W}$ & 1905.3 & 8.8 & 90 \\
\hline $30^{\circ}$ & $33.30^{\prime} \mathrm{W}$ & 1909.3 & 8.9 & 102 \\
\hline
\end{tabular}

TABLE 1 - Continued

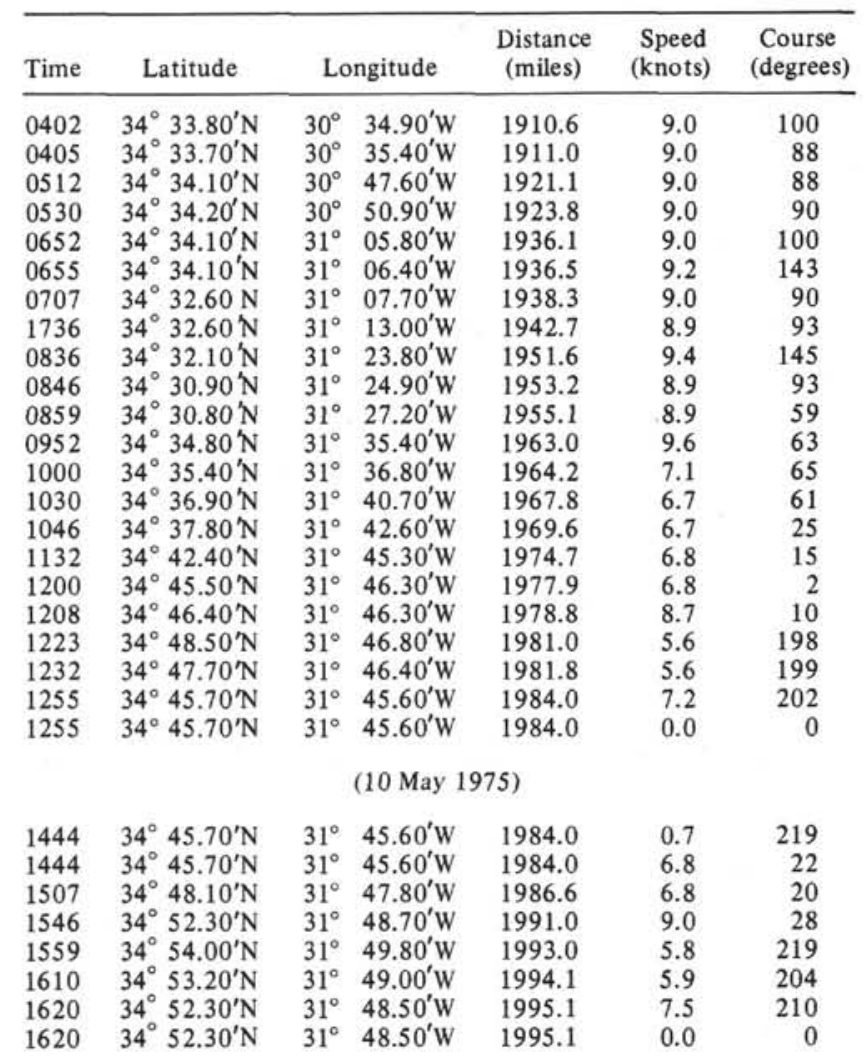

(12 May 1975)

$\begin{array}{llllllr}1830 & 34^{\circ} 52.30^{\prime} \mathrm{N} & 31^{\circ} & 48.50^{\prime} \mathrm{W} & 1995.1 & 0.8 & 95 \\ 1830 & 34^{\circ} 52.30^{\prime} \mathrm{N} & 31^{\circ} & 48.50^{\prime} \mathrm{W} & 1995.1 & 6.7 & 269 \\ 1855 & 34^{\circ} 52.30^{\prime} \mathrm{N} & 31^{\circ} & 45.10^{\prime} \mathrm{W} & 1997.8 & 8.6 & 270 \\ 1953 & 34^{\circ} 52.20^{\prime} \mathrm{N} & 31^{\circ} & 35.00^{\prime} \mathrm{W} & 2006.1 & 8.3 & 268 \\ 2010 & 34^{\circ} 52.10^{\prime} \mathrm{N} & 31^{\circ} & 32.10^{\prime} \mathrm{W} & 2008.5 & 8.5 & 268 \\ 2230 & 34^{\circ} 51.60^{\prime} \mathrm{N} & 31^{\circ} & 08.00^{\prime} \mathrm{W} & 2028.3 & 8.5 & 270 \\ 2332 & 34^{\circ} 51.50^{\prime} \mathrm{N} & 30^{\circ} & 57.30^{\prime} \mathrm{W} & 2037.1 & 8.8 & 272\end{array}$

(13 May 1975)

\begin{tabular}{rllllll}
000 & $34^{\circ} 51.70^{\prime} \mathrm{N}$ & $30^{\circ}$ & $52.30^{\prime} \mathrm{W}$ & 2041.2 & 8.8 & 272 \\
0030 & $34^{\circ} 51.90^{\prime} \mathrm{N}$ & $30^{\circ}$ & $46.90^{\prime} \mathrm{W}$ & 2045.6 & 8.8 & 270 \\
0116 & $34^{\circ} 51.90^{\prime} \mathrm{N}$ & $30^{\circ}$ & $38.70^{\prime} \mathrm{W}$ & 2052.3 & 9.1 & 271 \\
0210 & $34^{\circ} 52.00^{\prime} \mathrm{N}$ & $30^{\circ}$ & $28.70^{\prime} \mathrm{W}$ & 2060.5 & 8.7 & 270 \\
0354 & $34^{\circ} 51.90^{\prime} \mathrm{N}$ & $30^{\circ}$ & $10.40^{\prime} \mathrm{W}$ & 2075.6 & 8.4 & 270 \\
0414 & $34^{\circ} 51.90^{\prime} \mathrm{N}$ & $30^{\circ}$ & $07.00^{\prime} \mathrm{W}$ & 2078.4 & 8.8 & 269 \\
0542 & $34^{\circ} 51.60^{\prime} \mathrm{N}$ & $29^{\circ}$ & $51.20^{\prime} \mathrm{W}$ & 2091.3 & 8.9 & 270 \\
0602 & $34^{\circ} 51.60^{\prime} \mathrm{N}$ & $29^{\circ}$ & $47.60^{\prime} \mathrm{W}$ & 2094.3 & 8.5 & 270 \\
0940 & $34^{\circ} 51.60^{\prime} \mathrm{N}$ & $29^{\circ}$ & $09.90^{\prime} \mathrm{W}$ & 2125.2 & 8.5 & 269 \\
1000 & $34^{\circ} 51.50^{\prime} \mathrm{N}$ & $29^{\circ}$ & $06.40^{\prime} \mathrm{W}$ & 2128.1 & 8.5 & 266 \\
1058 & $34^{\circ} 50.90^{\prime} \mathrm{N}$ & $28^{\circ}$ & $56.40^{\prime} \mathrm{W}$ & 2136.3 & 8.3 & 266 \\
1232 & $34^{\circ} 50.10^{\prime} \mathrm{N}$ & $28^{\circ}$ & $40.60^{\prime} \mathrm{W}$ & 2149.3 & 7.9 & 266 \\
1252 & $34^{\circ} 49.90^{\prime} \mathrm{N}$ & $28^{\circ}$ & $37.40^{\prime} \mathrm{W}$ & 2151.9 & 8.5 & 267 \\
1318 & $34^{\circ} 49.70^{\prime} \mathrm{N}$ & $28^{\circ}$ & $32.90^{\prime} \mathrm{W}$ & 2155.6 & 8.1 & 268 \\
1418 & $34^{\circ} 49.40^{\prime} \mathrm{N}$ & $28^{\circ}$ & $23.00^{\prime} \mathrm{W}$ & 2163.8 & 8.4 & 268 \\
1500 & $34^{\circ} 49.20^{\prime} \mathrm{N}$ & $28^{\circ}$ & $15.80^{\prime} \mathrm{W}$ & 2169.7 & 8.8 & 270 \\
1650 & $34^{\circ} 49.20^{\prime} \mathrm{N}$ & $27^{\circ}$ & $56.20^{\prime} \mathrm{W}$ & 2185.8 & 8.9 & 270 \\
1710 & $34^{\circ} 49.20^{\prime} \mathrm{N}$ & $27^{\circ}$ & $52.60^{\prime} \mathrm{W}$ & 2188.7 & 8.8 & 269 \\
1858 & $34^{\circ} 48.90^{\prime} \mathrm{N}$ & $27^{\circ}$ & $33.30^{\prime} \mathrm{W}$ & 2204.6 & 8.7 & 268 \\
2050 & $34^{\circ} 48.40^{\prime} \mathrm{N}$ & $27^{\circ}$ & $13.50^{\prime} \mathrm{W}$ & 2220.8 & 8.7 & 267 \\
2256 & $34^{\circ} 47.40^{\prime} \mathrm{N}$ & $26^{\circ}$ & $51.30^{\prime} \mathrm{W}$ & 2239.1 & 9.1 & 260 \\
2315 & $34^{\circ} 46.90^{\prime} \mathrm{N}$ & $26^{\circ}$ & $47.80^{\prime} \mathrm{W}$ & 2242.0 & 8.7 & 342 \\
2328 & $34^{\circ} 48.70^{\prime} \mathrm{N}$ & $26^{\circ}$ & $47.10^{\prime} \mathrm{W}$ & 2243.9 & 9.1 & 260 \\
\hline
\end{tabular}


TABLE 1 - Continued

\begin{tabular}{|c|c|c|c|c|c|c|}
\hline Time & Latitude & & ngitude & $\begin{array}{c}\text { Distance } \\
\text { (miles) }\end{array}$ & $\begin{array}{c}\text { Speed } \\
\text { (knots) }\end{array}$ & $\begin{array}{l}\text { Course } \\
\text { (degree }\end{array}$ \\
\hline \multicolumn{7}{|c|}{ (14 May 1975) } \\
\hline 000 & $34^{\circ} 47.90^{\prime} \mathrm{N}$ & $26^{\circ}$ & $41.30^{\prime} \mathrm{W}$ & 2248.7 & 9.1 & 263 \\
\hline 0028 & $34^{\circ} 47.40^{\prime} \mathrm{N}$ & $26^{\circ}$ & $36.20^{\prime} \mathrm{W}$ & 2252.9 & 8.9 & 264 \\
\hline 0048 & $34^{\circ} 47.10^{\prime} \mathrm{N}$ & $26^{\circ}$ & $32.60^{\prime} W$ & 2255.9 & 9.2 & 266 \\
\hline 0208 & $34^{\circ} 46.30^{\prime} \mathrm{N}$ & $26^{\circ}$ & $17.70^{\prime} \mathrm{W}$ & 2268.2 & 9.4 & 268 \\
\hline 0248 & $34^{\circ} 46.00^{\prime} \mathrm{N}$ & $26^{\circ}$ & $10.10^{\prime} \mathrm{W}$ & 2274.5 & 9.4 & 272 \\
\hline 0304 & $34^{\circ} 46.10^{\prime} \mathrm{N}$ & $26^{\circ}$ & $07.00^{\prime} \mathrm{W}$ & 2277.0 & 9.3 & 272 \\
\hline 0320 & $34^{\circ} 46.20^{\prime} \mathrm{N}$ & $26^{\circ}$ & $04.00^{\prime} \mathrm{W}$ & 2279.5 & 9.3 & 276 \\
\hline 0354 & $34^{\circ} 46.70^{\prime} \mathrm{N}$ & $25^{\circ}$ & $57.60 \mathrm{~W}$ & 2284.7 & 8.5 & 278 \\
\hline 0440 & $34^{\circ} 47.60^{\prime} \mathrm{N}$ & $25^{\circ}$ & $49.70^{\prime} \mathrm{W}$ & 2291.3 & 8.5 & 275 \\
\hline 0450 & $34^{\circ} 47.70^{\prime} \mathrm{N}$ & $25^{\circ}$ & $48.00^{\prime} W$ & 2292.7 & 9.6 & 274 \\
\hline 0510 & $34^{\circ} 47.90^{\prime} \mathrm{N}$ & $25^{\circ}$ & $44.10^{\prime} \mathrm{W}$ & 2295.9 & 9.2 & 277 \\
\hline 0652 & $34^{\circ} 49.70^{\prime} \mathrm{N}$ & $25^{\circ}$ & $25.10^{\prime} \mathrm{W}$ & 2311.6 & 9.3 & 277 \\
\hline 0710 & $34^{\circ} 50.00^{\prime} \mathrm{N}$ & $25^{\circ}$ & $21.70^{\prime} \mathrm{W}$ & 2314.4 & 9.3 & 275 \\
\hline 0745 & $34^{\circ} 50.40^{\prime} \mathrm{N}$ & $25^{\circ}$ & $15.10^{\prime} \mathrm{W}$ & 2319.8 & 9.3 & 271 \\
\hline 0835 & $34^{\circ} 50.60^{\prime} \mathrm{N}$ & $25^{\circ}$ & $05.70^{\prime} \mathrm{W}$ & 2327.5 & 9.3 & 268 \\
\hline 0842 & $34^{\circ} 50.60^{\prime} \mathrm{N}$ & $25^{\circ}$ & $04.40^{\prime} \mathrm{W}$ & 2328.6 & 8.4 & 269 \\
\hline 1012 & $34^{\circ} 50.30^{\prime} \mathrm{N}$ & $24^{\circ}$ & $49.10^{\prime} \mathrm{W}$ & 2341.2 & 7.4 & 266 \\
\hline 1043 & $34^{\circ} 50.00^{\prime} \mathrm{N}$ & $24^{\circ}$ & $44.50^{\prime} \mathrm{W}$ & 2345.0 & 7.5 & 292 \\
\hline 1142 & $34^{\circ} 52.70^{\prime} \mathrm{N}$ & $24^{\circ}$ & $36.20^{\prime} \mathrm{W}$ & 2352.3 & 7.4 & 288 \\
\hline 1144 & $34^{\circ} 52.80^{\prime} \mathrm{N}$ & $24^{\circ}$ & $35.90^{\prime} \mathrm{W}$ & 2352.5 & 7.4 & 288 \\
\hline 1330 & $34^{\circ} 56.80^{\prime} \mathrm{N}$ & $24^{\circ}$ & $20.70^{\prime} \mathrm{W}$ & 2365.6 & 8.1 & 287 \\
\hline 1336 & $34^{\circ} 57.00^{\prime} \mathrm{N}$ & $24^{\circ}$ & $19.80^{\prime} \mathrm{W}$ & 2366.4 & 8.1 & 279 \\
\hline 1355 & $34^{\circ} 57.40^{\prime} \mathrm{N}$ & $24^{\circ}$ & $16.70^{\prime} \mathrm{W}$ & 2369.0 & 5.1 & 280 \\
\hline 1417 & $34^{\circ} 57.80^{\prime} \mathrm{N}$ & $24^{\circ}$ & $14.40^{\prime} \mathrm{W}$ & 2370.9 & 8.1 & 279 \\
\hline 1540 & $34^{\circ} 59.60^{\prime} \mathrm{N}$ & $24^{\circ}$ & $01.00^{\prime} \mathrm{W}$ & 2382.0 & 7.8 & 278 \\
\hline 1710 & $35^{\circ} 01.20^{\prime} \mathrm{N}$ & $23^{\circ}$ & $46.80^{\prime} \mathrm{W}$ & 2393.8 & 7.8 & 273 \\
\hline 1752 & $35^{\circ} 01.50^{\prime} \mathrm{N}$ & $23^{\circ}$ & $40.10^{\prime} \mathrm{W}$ & 2399.3 & 7.5 & 271 \\
\hline 2146 & $35^{\circ} 02.20^{\prime} \mathrm{N}$ & $23^{\circ}$ & $04.60^{\prime} \mathrm{W}$ & 2428.3 & 7.8 & 276 \\
\hline 2210 & $35^{\circ} 02.50^{\prime} \mathrm{N}$ & $23^{\circ}$ & $00.80^{\prime} \mathrm{W}$ & 2431.5 & 7.7 & 272 \\
\hline 2230 & $35^{\circ} 02.60^{\prime} \mathrm{N}$ & $22^{\circ}$ & $57.70^{\prime} \mathrm{W}$ & 2434.0 & 7.7 & 277 \\
\hline 2342 & $35^{\circ} 03.80^{\prime} \mathrm{N}$ & $22^{\circ}$ & $46.50^{\prime} \mathrm{W}$ & 2443.2 & 7.2 & 281 \\
\hline
\end{tabular}

(15 May 1975)

$\begin{array}{rllllll}000 & 35^{\circ} 04.20^{\prime} \mathrm{N} & 22^{\circ} & 43.90^{\prime} \mathrm{W} & 2445.4 & 7.7 & 281 \\ 000 & 35^{\circ} 04.20^{\prime} \mathrm{N} & 22^{\circ} & 43.90^{\prime} \mathrm{W} & 2445.4 & 7.7 & 281 \\ 0102 & 35^{\circ} 05.70^{\prime} \mathrm{N} & 22^{\circ} & 34.30^{\prime} \mathrm{W} & 2453.4 & 7.2 & 279 \\ 0242 & 35^{\circ} 07.60^{\prime} \mathrm{N} & 22^{\circ} & 19.80^{\prime} \mathrm{W} & 2465.4 & 7.2 & 275 \\ 0246 & 35^{\circ} 07.60^{\prime} \mathrm{N} & 22^{\circ} & 19.20^{\prime} \mathrm{W} & 2465.9 & 7.8 & 274 \\ 0315 & 35^{\circ} 07.90^{\prime} \mathrm{N} & 22^{\circ} & 14.60^{\prime} \mathrm{W} & 2469.7 & 7.8 & 272 \\ 0320 & 35^{\circ} 07.90^{\prime} \mathrm{N} & 22^{\circ} & 13.80^{\prime} \mathrm{W} & 2470.3 & 7-8 & 276 \\ 0402 & 35^{\circ} 08.50^{\prime} \mathrm{N} & 22^{\circ} & 07.20^{\prime} \mathrm{W} & 2475.8 & 7.5 & 275 \\ 0432 & 35^{\circ} 08.80^{\prime} \mathrm{N} & 22^{\circ} & 02.60^{\prime} \mathrm{W} & 2479.5 & 7.7 & 276 \\ 0550 & 35^{\circ} 09.90^{\prime} \mathrm{N} & 21^{\circ} & 50.50^{\prime} \mathrm{W} & 2489.5 & 7.6 & 274 \\ 0711 & 35^{\circ} 10.70^{\prime} \mathrm{N} & 21^{\circ} & 38.10^{\prime} \mathrm{W} & 2499.7 & 7.5 & 265 \\ 0736 & 35^{\circ} 10.40^{\prime} \mathrm{N} & 21^{\circ} & 34.20^{\prime} \mathrm{W} & 2502.8 & 5.8 & 265 \\ 0748 & 35^{\circ} 10.30^{\prime} \mathrm{N} & 21^{\circ} & 32.80^{\prime} \mathrm{W} & 2504.0 & 6.6 & 269 \\ 0808 & 35^{\circ} 10.30^{\prime} \mathrm{N} & 21^{\circ} & 30.10^{\prime} \mathrm{W} & 2506.2 & 6.5 & 261 \\ 0835 & 35^{\circ} 09.80^{\prime} \mathrm{N} & 21^{\circ} & 26.60^{\prime} \mathrm{W} & 2509.1 & 5.3 & 262 \\ 0844 & 35^{\circ} 09.70^{\prime} \mathrm{N} & 21^{\circ} & 25.60^{\prime} \mathrm{W} & 2509.9 & 6.7 & 260 \\ 0844 & 35^{\circ} 09.70^{\prime} \mathrm{N} & 21^{\circ} & 25.60^{\prime} \mathrm{W} & 2509.0 & 0.0 & 0\end{array}$

(16 May 1975)

$\begin{array}{rllllll}1736 & 35^{\circ} 09.70^{\prime} \mathrm{N} & 21^{\circ} & 25.60^{\prime} \mathrm{W} & 2509.9 & 1.0 & 221 \\ 1736 & 35^{\circ} 09.70^{\prime} \mathrm{N} & 21^{\circ} & 25.60^{\prime} \mathrm{W} & 2509.9 & 5.8 & 78 \\ 1749 & 35^{\circ} 10.00^{\prime} \mathrm{N} & 21^{\circ} & 27.10^{\prime} \mathrm{W} & 2511.2 & 8.8 & 77 \\ 1802 & 35^{\circ} 10.40^{\prime} \mathrm{N} & 21^{\circ} & 29.40^{\prime} \mathrm{W} & 2513.1 & 8.6 & 73 \\ 1950 & 35^{\circ} 14.90^{\prime} \mathrm{N} & 21^{\circ} & 46.50^{\prime} \mathrm{W} & 2528.6 & 8.7 & 74 \\ 2138 & 35^{\circ} 19.10^{\prime} \mathrm{N} & 22^{\circ} & 05.90^{\prime} \mathrm{W} & 2544.2 & 8.6 & 74 \\ 2230 & 35^{\circ} 20.80^{\prime} \mathrm{N} & 22^{\circ} & 13.00^{\prime} \mathrm{W} & 2550.2 & 8.8 & 76 \\ 2300 & 35^{\circ} 22.30^{\prime} \mathrm{N} & 22^{\circ} & 20.00^{\prime} \mathrm{W} & 2556.1 & 8.8 & 73 \\ 2348 & 35^{\circ} 24.30^{\prime} \mathrm{N} & 22^{\circ} & 28.30^{\prime} \mathrm{W} & 2563.2 & 9.2 & 73 \\ & & & (17 \mathrm{May} 1975) & & \\ 000 & 35^{\circ} 24.80^{\prime} \mathrm{N} & 22^{\circ} & 30.50^{\prime} \mathrm{W} & 2565.0 & 9.2 & 73 \\ 0008 & 35^{\circ} 25.20^{\prime} \mathrm{N} & 22^{\circ} & 31.90^{\prime} \mathrm{W} & 2566.2 & 8.7 & 72 \\ 0030 & 35^{\circ} 26.20^{\prime} \mathrm{N} & 22^{\circ} & 35.60^{\prime} \mathrm{W} & 2569.4 & 8.7 & 69 \\ 0134 & 35^{\circ} 29.50^{\prime} \mathrm{N} & 22^{\circ} & 46.30^{\prime} \mathrm{W} & 2578.7 & 8.4 & 68 \\ 0218 & 35^{\circ} 31.80^{\prime} \mathrm{N} & 22^{\circ} & 53.30^{\prime} \mathrm{W} & 2584.9 & 8.7 & 67\end{array}$

\begin{tabular}{rrrrrrr}
000 & $38^{\circ} 20.50^{\prime} \mathrm{N}$ & $25^{\circ}$ & $45.00^{\prime} \mathrm{W}$ & 2854.1 & 8.4 & 355 \\
0030 & $38^{\circ} 24.60^{\prime} \mathrm{N}$ & $25^{\circ}$ & $44.50^{\prime} \mathrm{W}$ & 2858.3 & 8.4 & 359 \\
0042 & $38^{\circ} 26.30^{\prime} \mathrm{N}$ & $25^{\circ}$ & $44.50^{\prime} \mathrm{W}$ & 2859.9 & 8.7 & 358 \\
0100 & $38^{\circ} 28.90^{\prime} \mathrm{N}$ & $25^{\circ}$ & $44.40^{\prime} \mathrm{W}$ & 2862.5 & 8.5 & 0 \\
0246 & $38^{\circ} 44.00^{\prime} \mathrm{N}$ & $25^{\circ}$ & $44.50^{\prime} \mathrm{W}$ & 2877.6 & 8.7 & 359 \\
0250 & $38^{\circ} 44.60^{\prime} \mathrm{N}$ & $25^{\circ}$ & $44.50^{\prime} \mathrm{W}$ & 2878.2 & 8.7 & 1 \\
0332 & $38^{\circ} 50.70^{\prime} \mathrm{N}$ & $25^{\circ}$ & $44.60^{\prime} \mathrm{W}$ & 2884.3 & 12.5 & 359 \\
0750 & $39^{\circ} 44.60^{\prime} \mathrm{N}$ & $25^{\circ}$ & $43.80^{\prime} \mathrm{W}$ & 2938.2 & 12.4 & 7 \\
0834 & $39^{\circ} 53.60^{\prime} \mathrm{N}$ & $25^{\circ}$ & $45.30^{\prime} \mathrm{W}$ & 2947.3 & 9.7 & 32 \\
0857 & $39^{\circ} 56.80^{\prime} \mathrm{N}$ & $25^{\circ}$ & $47.80^{\prime} \mathrm{W}$ & 2951.0 & 10.1 & 39 \\
0918 & $39^{\circ} 59.50^{\prime} \mathrm{N}$ & $25^{\circ}$ & $50.70^{\prime} \mathrm{W}$ & 2954.6 & 5.9 & 54 \\
& & & & & & \\
1250 & $41^{\circ} 34.00^{\prime} \mathrm{N}$ & $28^{\circ}$ & $45.80^{\prime} \mathrm{W}$ & 3117.4 & 3.3 & 113 \\
\hline
\end{tabular}

\begin{tabular}{llccc}
\hline Time Latitude $\quad$ Longitude & $\begin{array}{c}\text { Distance } \\
\text { (miles) }\end{array}$ & $\begin{array}{c}\text { Speed } \\
\text { (knots) }\end{array}$ & $\begin{array}{c}\text { Course } \\
\text { (degrees) }\end{array}$ \\
\hline
\end{tabular}

$\begin{array}{lllllrr}0324 & 35^{\circ} 35.60^{\prime} \mathrm{N} & 23^{\circ} & 04.10^{\prime} \mathrm{W} & 2594.4 & 8.8 & 68 \\ 0354 & 35^{\circ} 37.20^{\prime} \mathrm{N} & 23^{\circ} & 09.10^{\prime} \mathrm{W} & 2598.8 & 8.8 & 71 \\ 0404 & 35^{\circ} 37.70^{\prime} \mathrm{N} & 23^{\circ} & 10.80^{\prime} \mathrm{W} & 2600.3 & 8.8 & 70 \\ 0424 & 35^{\circ} 38.70^{\prime} \mathrm{N} & 23^{\circ} & 14.20^{\prime} \mathrm{W} & 2603.2 & 9.4 & 71 \\ 0520 & 35^{\circ} 41.60^{\prime} \mathrm{N} & 23^{\circ} & 24.40^{\prime} \mathrm{W} & 2612.0 & 9.4 & 76 \\ 0600 & 35^{\circ} 43.10^{\prime} \mathrm{N} & 23^{\circ} & 31.90^{\prime} \mathrm{W} & 2618.3 & 9.5 & 75 \\ 0640 & 35^{\circ} 44.70^{\prime} \mathrm{N} & 23^{\circ} & 39.40^{\prime} \mathrm{W} & 2624.6 & 9.5 & 85 \\ 0810 & 35^{\circ} 46.00^{\prime} \mathrm{N} & 23^{\circ} & 57.00^{\prime} \mathrm{W} & 2638.9 & 9.5 & 81 \\ 1102 & 35^{\circ} 50.20^{\prime} \mathrm{N} & 24^{\circ} & 30.20^{\prime} \mathrm{W} & 2666.2 & 9.3 & 82 \\ 1120 & 35^{\circ} 50.60^{\prime} \mathrm{N} & 24^{\circ} & 33.60^{\prime} \mathrm{W} & 2668.9 & 9.3 & 84 \\ 1140 & 35^{\circ} 50.90^{\prime} \mathrm{N} & 24^{\circ} & 37.40^{\prime} \mathrm{W} & 2672.0 & 9.3 & 86 \\ 1248 & 35^{\circ} 51.70^{\prime} \mathrm{N} & 24^{\circ} & 50.30^{\prime} \mathrm{W} & 2682.5 & 9.7 & 86 \\ 1308 & 35^{\circ} 51.90^{\prime} \mathrm{N} & 24^{\circ} & 54.30^{\prime} \mathrm{W} & 2685.8 & 8.7 & 85 \\ 1318 & 35^{\circ} 52.00^{\prime} \mathrm{N} & 24^{\circ} & 56.10^{\prime} \mathrm{W} & 2687.2 & 8.7 & 90 \\ 1336 & 35^{\circ} 52.00^{\prime} \mathrm{N} & 24^{\circ} & 59.30^{\prime} \mathrm{W} & 2689.9 & 8.7 & 86 \\ 1406 & 35^{\circ} 52.30^{\prime} \mathrm{N} & 25^{\circ} & 04.70^{\prime} \mathrm{W} & 2694.2 & 10.6 & 91 \\ 1414 & 35^{\circ} 52.30^{\prime} \mathrm{N} & 25^{\circ} & 06.40^{\prime} \mathrm{W} & 2695.6 & 8.9 & 1 \\ 1429 & 35^{\circ} 54.50^{\prime} \mathrm{N} & 25^{\circ} & 06.50^{\prime} \mathrm{W} & 2697.8 & 8.9 & 6 \\ 1430 & 35^{\circ} 54.60^{\prime} \mathrm{N} & 25^{\circ} & 06.50^{\prime} \mathrm{W} & 2698.0 & 6.1 & 20 \\ 1441 & 35^{\circ} 55.70^{\prime} \mathrm{N} & 25^{\circ} & 07.00^{\prime} \mathrm{W} & 2699.1 & 6.7 & 10 \\ 1441 & 35^{\circ} 55.70^{\prime} \mathrm{N} & 25^{\circ} & 07.00^{\prime} \mathrm{W} & 2699.1 & 0.0 & 0\end{array}$

(19 May 1975)

\begin{tabular}{|c|c|c|c|c|c|c|}
\hline 0455 & $35^{\circ} 55.70^{\prime} \mathrm{N}$ & $25^{\circ}$ & $07.00^{\prime} \mathrm{W}$ & 2699.1 & 1.3 & 211 \\
\hline 0455 & $35^{\circ} 55.70^{\prime} \mathrm{N}$ & $25^{\circ}$ & $07.00^{\prime} \mathrm{W}$ & 2699.1 & 6.3 & 48 \\
\hline 0509 & $35^{\circ} 56.70^{\prime} \mathrm{N}$ & $25^{\circ}$ & $08.30^{\prime} W$ & 2700.6 & 8.5 & 47 \\
\hline 0558 & $36^{\circ} 01.40^{\prime} \mathrm{N}$ & $25^{\circ}$ & $14.60^{\circ} \mathrm{W}$ & 2707.5 & 8.3 & 47 \\
\hline 0730 & $36^{\circ} 10.20^{\prime} \mathrm{N}$ & $25^{\circ}$ & $26.10^{\prime} \mathrm{W}$ & 2720.3 & 8.3 & 28 \\
\hline 0852 & $36^{\circ} 20.20^{\prime} \mathrm{N}$ & $25^{\circ}$ & $32.60^{\prime} \mathrm{W}$ & 2731.6 & 8.4 & 13 \\
\hline 1005 & $36^{\circ} 30.10^{\prime} \mathrm{N}$ & $25^{\circ}$ & $35.40^{\prime} \mathrm{W}$ & 2741.8 & 8.4 & 10 \\
\hline 1110 & $36^{\circ} 39.10^{\prime} \mathrm{N}$ & $25^{\circ}$ & $37.50^{\circ} \mathrm{W}$ & 2750.9 & 8.1 & 16 \\
\hline 1117 & $36^{\circ} 40.00^{\prime} \mathrm{N}$ & $25^{\circ}$ & $37.80^{\prime} \mathrm{W}$ & 2751.9 & 8.1 & 18 \\
\hline 1205 & $36^{\circ} 46.10^{\prime} \mathrm{N}$ & $25^{\circ}$ & $40.30^{\prime} \mathrm{W}$ & 2758.3 & 8.1 & 16 \\
\hline 1210 & $36^{\circ} 46.80^{\prime} \mathrm{N}$ & $25^{\circ}$ & $40.60^{\prime} \mathrm{W}$ & 2759.0 & 8.2 & 29 \\
\hline 1219 & $36^{\circ} 47.90^{\prime} \mathrm{N}$ & $25^{\circ}$ & $41.30 \%$ & 2760.2 & 8.2 & 35 \\
\hline 1257 & $36^{\circ} 52.10^{\prime} \mathrm{N}$ & $25^{\circ}$ & $45.10^{\prime} \mathrm{W}$ & 2765.4 & 8.0 & 7 \\
\hline 1324 & $36^{\circ} 55.70^{\prime} \mathrm{N}$ & $25^{\circ}$ & $45.60^{\prime} \mathrm{W}$ & 2769.1 & 8.1 & 352 \\
\hline 1338 & $36^{\circ} 57.60^{\prime} \mathrm{N}$ & $25^{\circ}$ & $45.30^{\prime} \mathrm{W}$ & 2770.9 & 7.9 & 352 \\
\hline 1422 & $37^{\circ} 03.30^{\prime} \mathrm{N}$ & $25^{\circ}$ & $44.30^{\circ} \mathrm{W}$ & 2776.7 & 7.9 & 359 \\
\hline 1454 & $37^{\circ} 07.50^{\prime} \mathrm{N}$ & $25^{\circ}$ & $44.20^{\prime} \mathrm{W}$ & 2780.9 & 7.9 & 3 \\
\hline 1526 & $37^{\circ} 11.70^{\prime} \mathrm{N}$ & $25^{\circ}$ & $44.50^{\prime} \mathrm{W}$ & 2785.1 & 8.1 & 3 \\
\hline 1608 & $37^{\circ} 17.30^{\prime} \mathrm{N}$ & $25^{\circ}$ & $44.90^{\circ} \mathrm{W}$ & 2790.8 & 8.1 & 7 \\
\hline 1730 & $37^{\circ} 28.30^{\prime} \mathrm{N}$ & $25^{\circ}$ & $46.50^{\prime} \mathrm{W}$ & 2801.8 & 8.1 & 3 \\
\hline 1806 & $37^{\circ} 33.10^{\prime} \mathrm{N}$ & $25^{\circ}$ & $46.90 \%$ & 2806.6 & 8.1 & 360 \\
\hline 2038 & $37^{\circ} 53.60^{\prime} \mathrm{N}$ & $25^{\circ}$ & $46.70^{\prime} W$ & 2827.1 & 7.8 & 358 \\
\hline 2130 & $38^{\circ} 00.30^{\prime} \mathrm{N}$ & $25^{\circ}$ & $46.40^{\prime} \mathrm{W}$ & 2833.8 & 7.8 & 356 \\
\hline 2142 & $38^{\circ} 01.90^{\prime} \mathrm{N}$ & $25^{\circ}$ & $46.30^{\prime} \mathrm{W}$ & 2835.4 & 8.1 & 356 \\
\hline 2218 & $38^{\circ} 06.80^{\prime} \mathrm{N}$ & $25^{\circ}$ & $45.80^{\prime} \mathrm{W}$ & 2840.3 & 8.1 & 10 \\
\hline 2241 & $38^{\circ} 09.80^{\prime} \mathrm{N}$ & $25^{\circ}$ & $46.50^{\prime} \mathrm{W}$ & 2843.4 & 8.1 & 353 \\
\hline 2310 & $38^{\circ} 13.70^{\prime} \mathrm{N}$ & $25^{\circ}$ & $45.90^{\prime} \mathrm{W}$ & 2847.3 & 7.9 & 353 \\
\hline 2330 & $38^{\circ} 16.30^{\prime} \mathrm{N}$ & $25^{\circ}$ & $45.50^{\prime} \mathrm{W}$ & 2849.9 & 8.4 & 355 \\
\hline
\end{tabular}

(20 May 1975) 


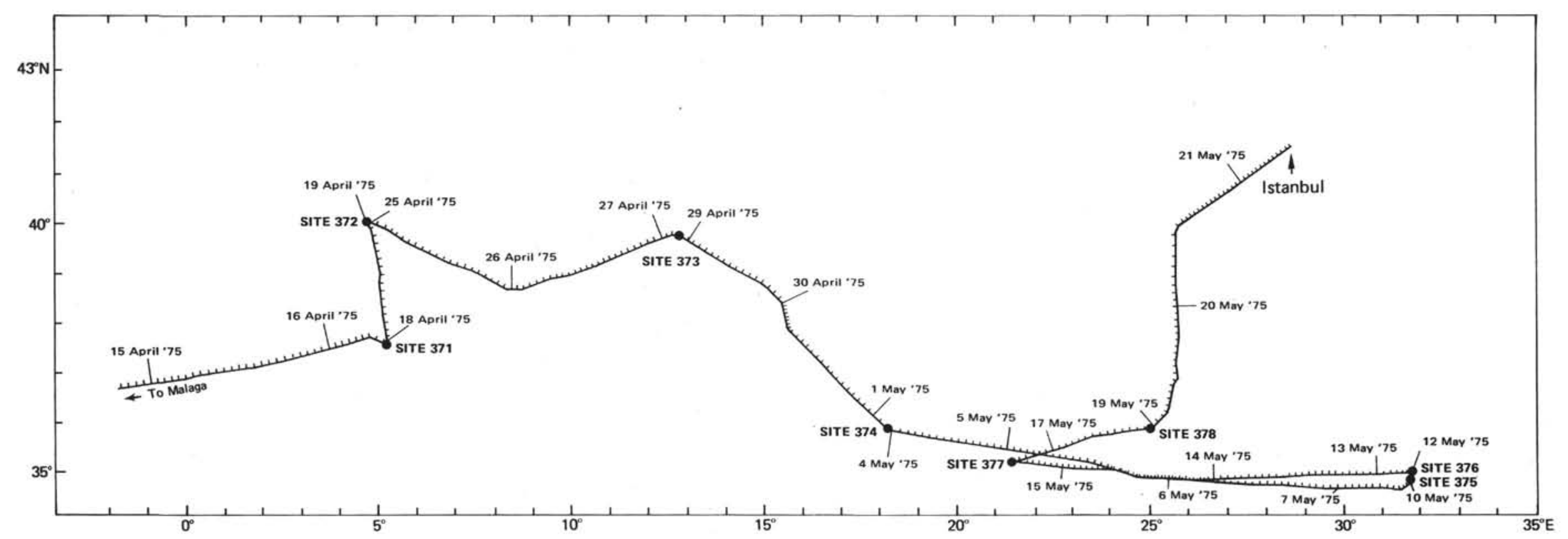

Figure 1. 

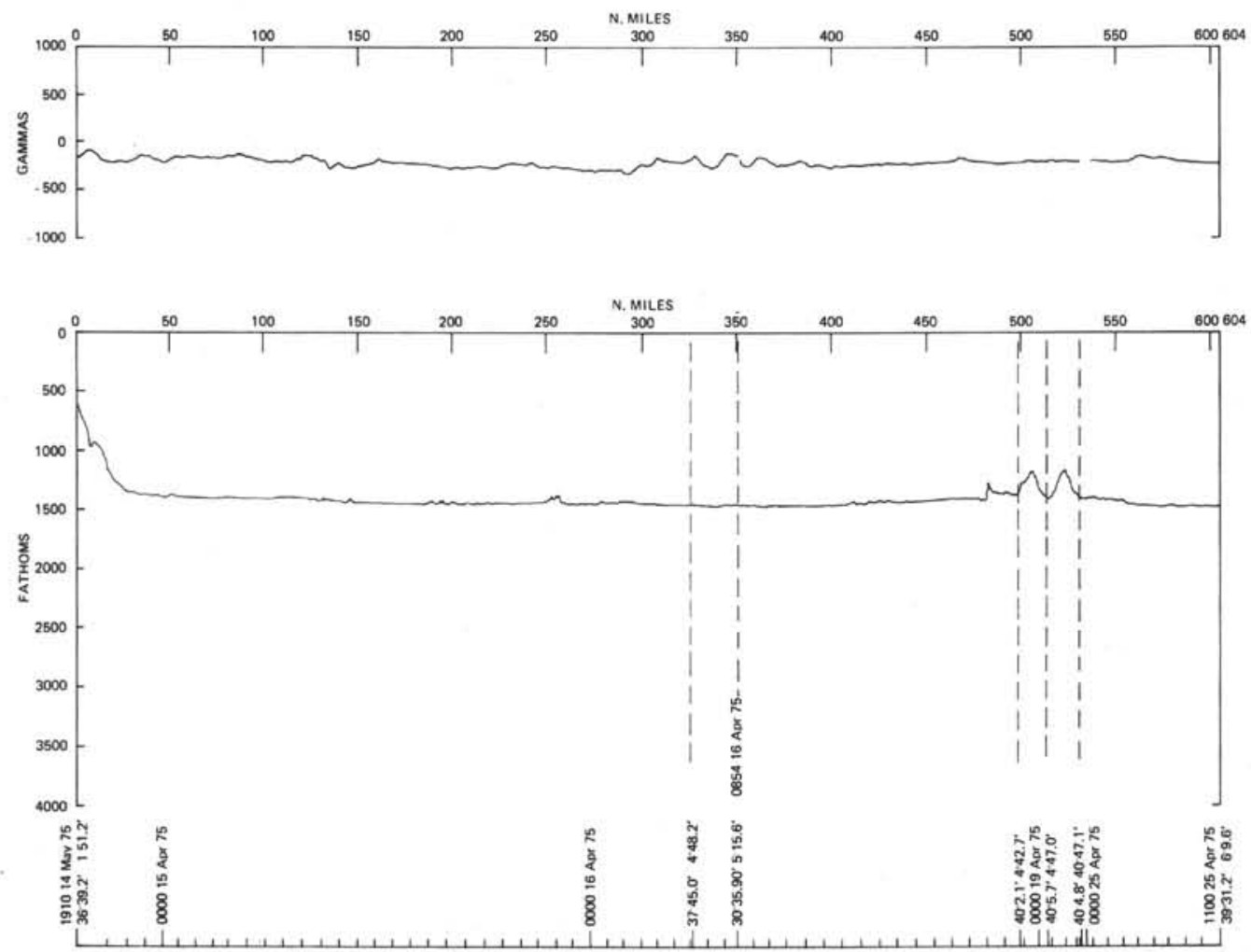

Figure 2.
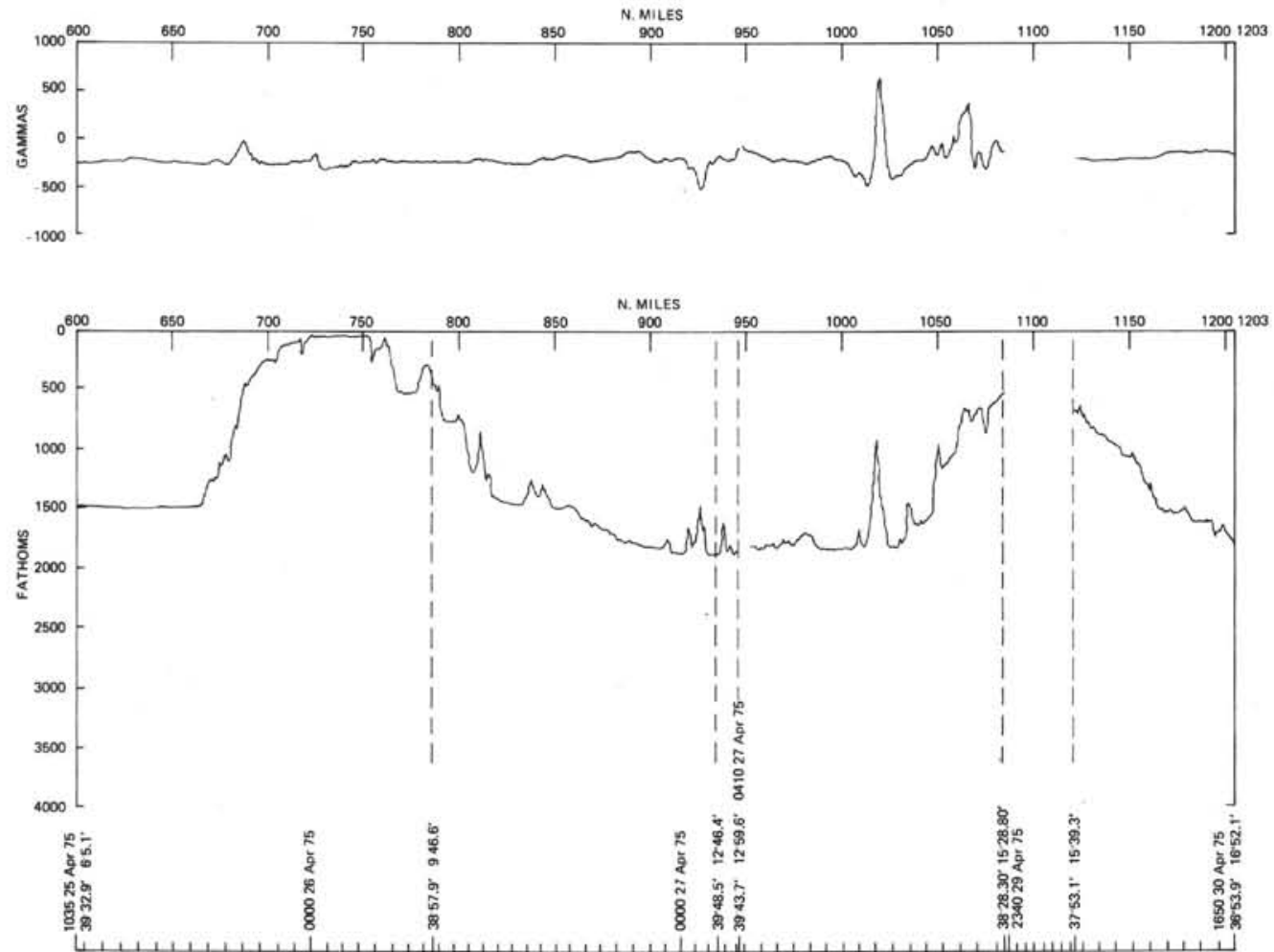

Figure 2-- Continued 

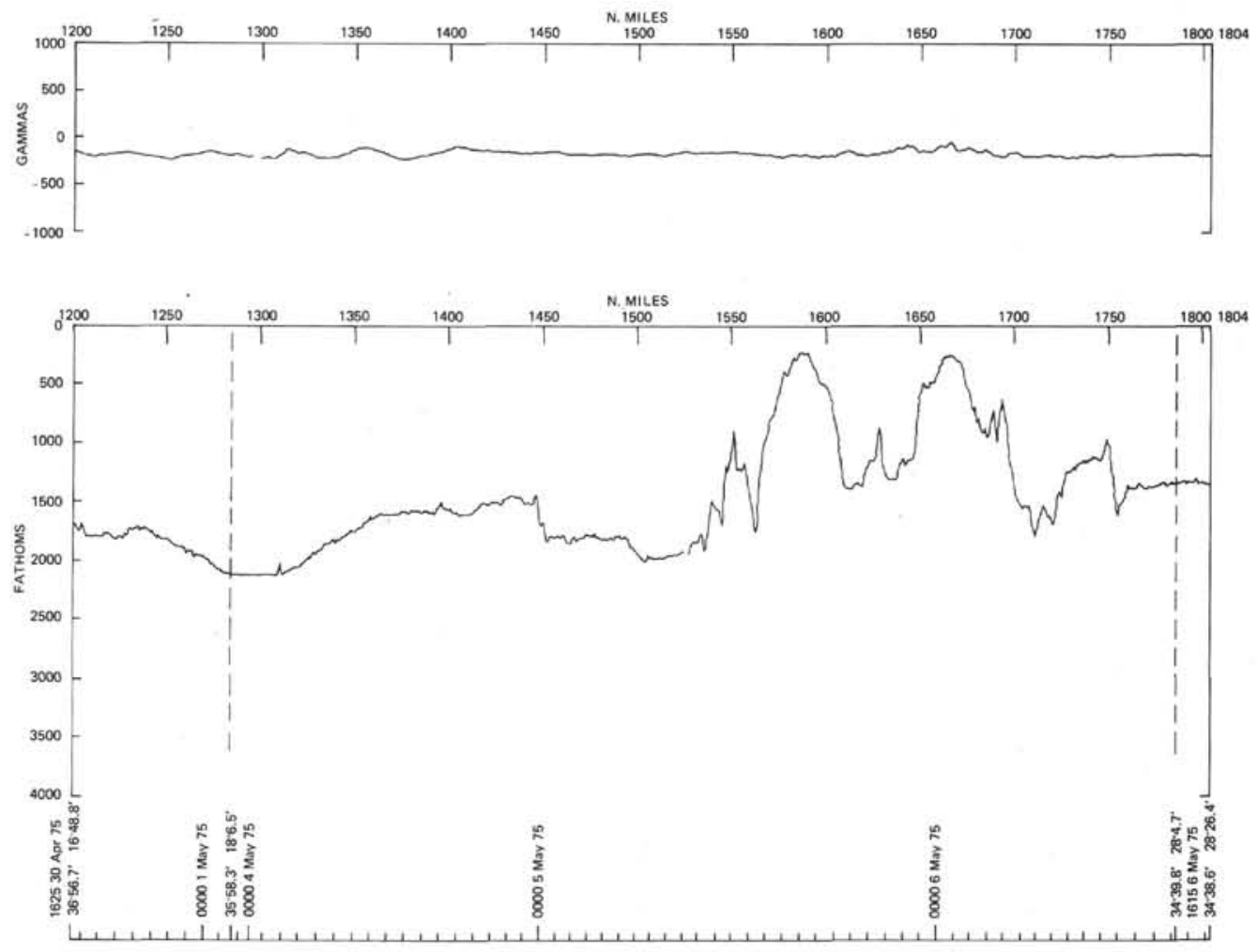

Figure 2-Continued
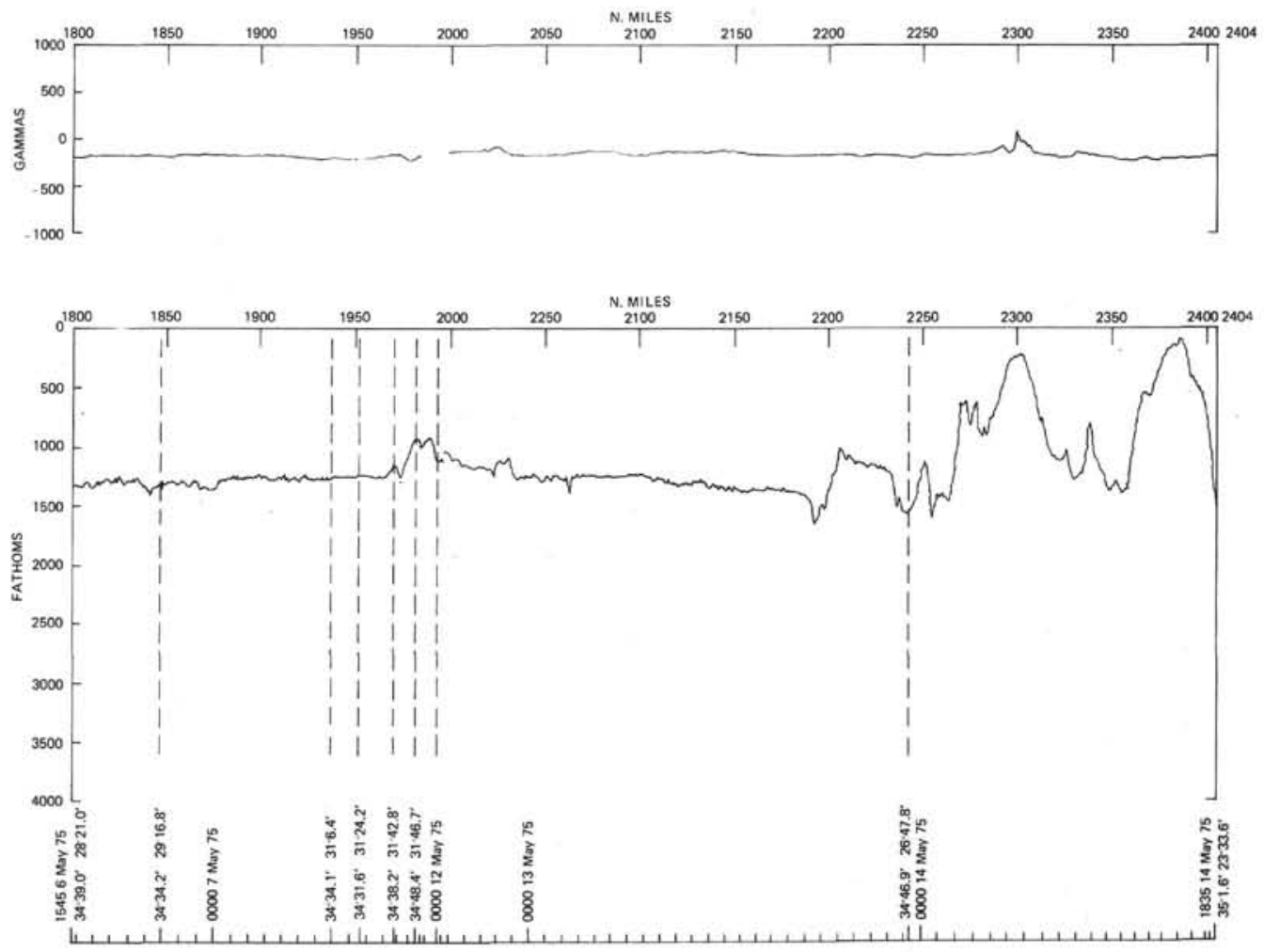

Figure 2 -Continued 

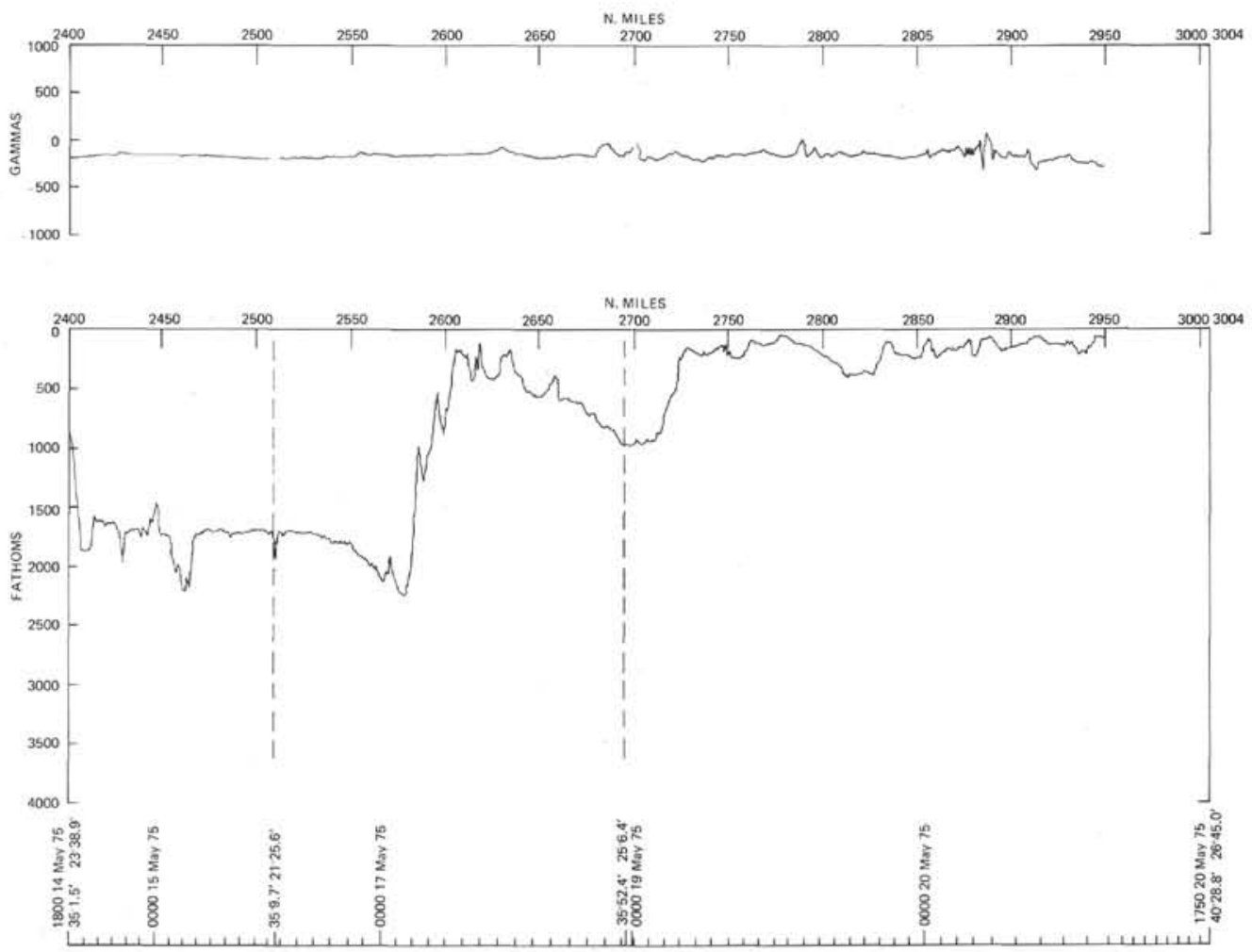

Figure 2 - Continued
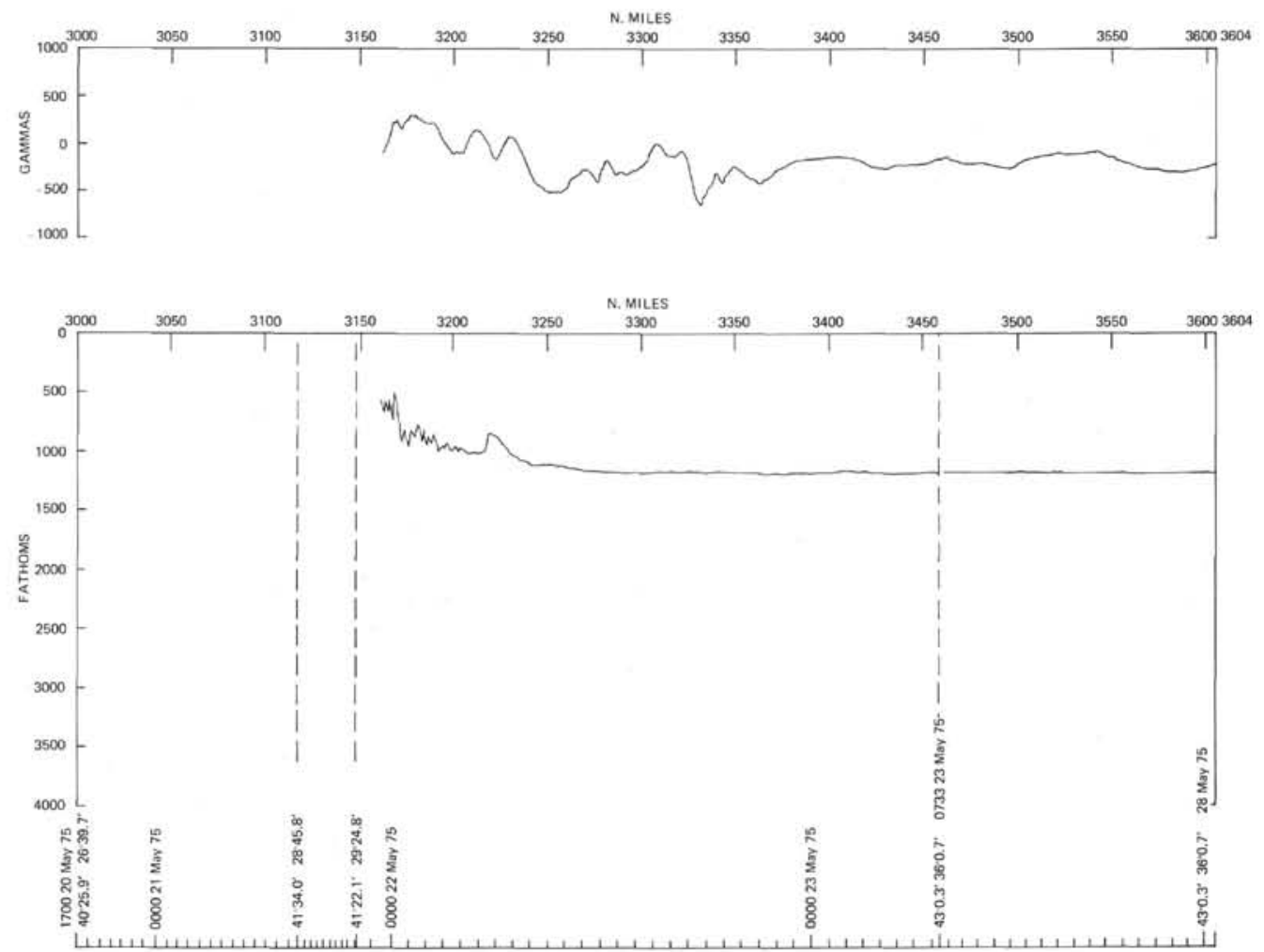

Figure 2-Continued 

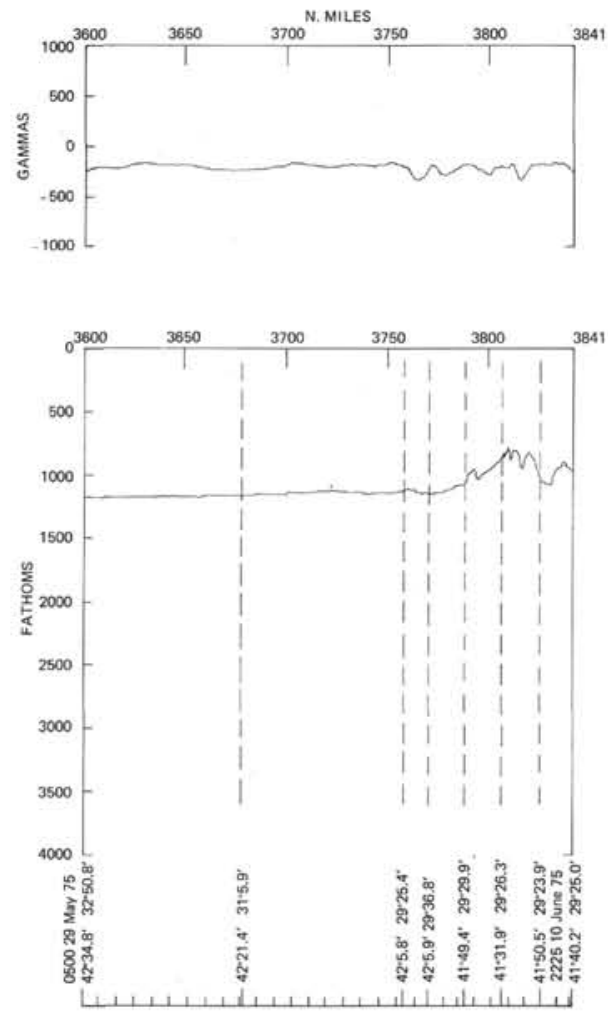

Figure 2 -Continued 

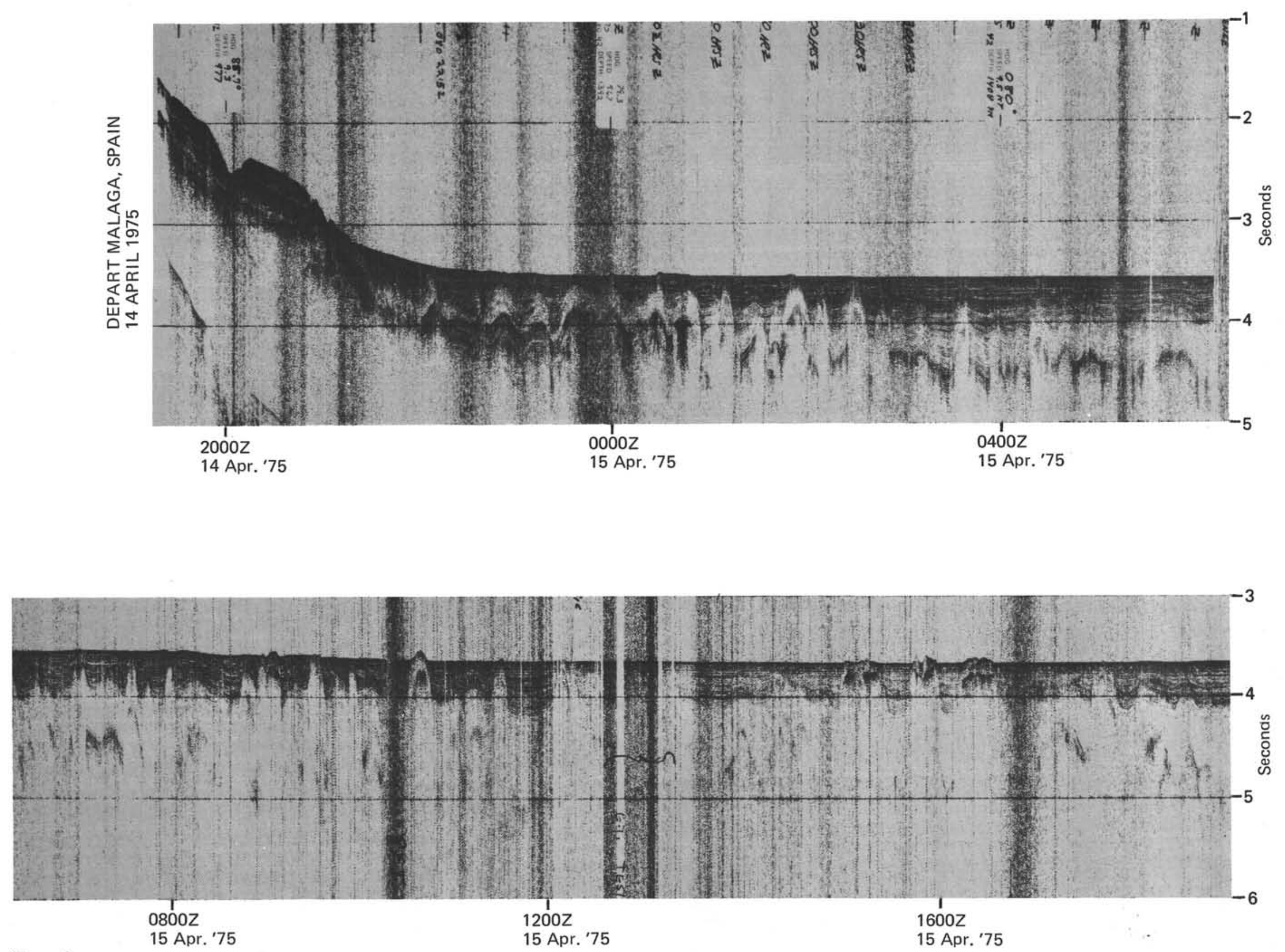

Figure 3

15 Apr. '75

15 Apr. '75

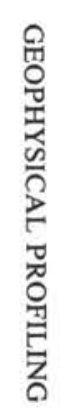




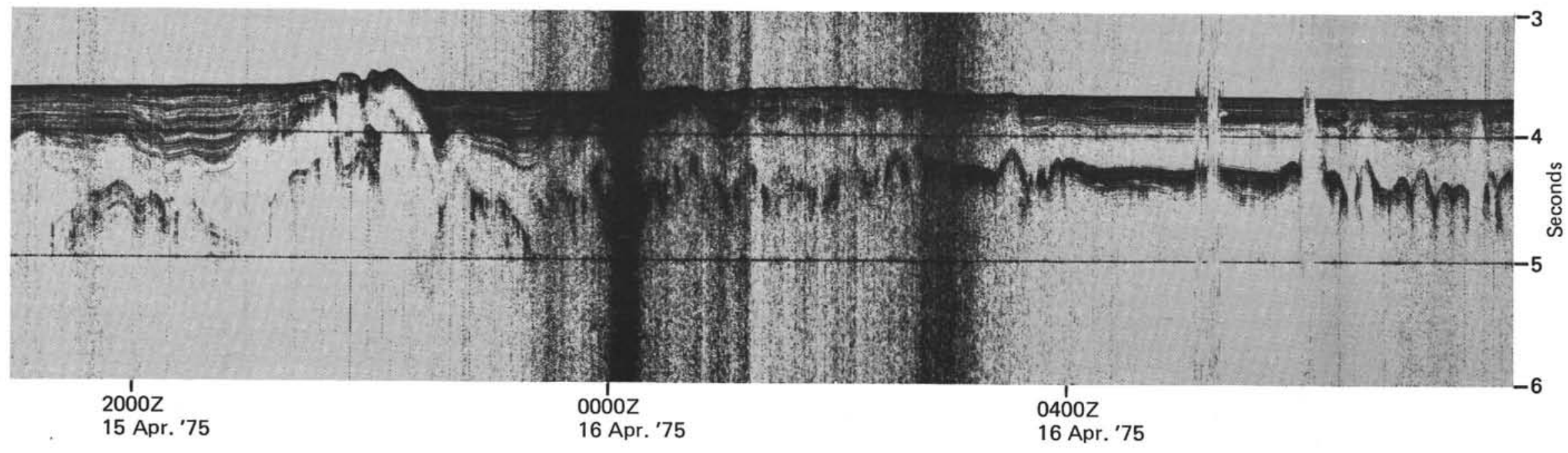

\section{SITE 371}

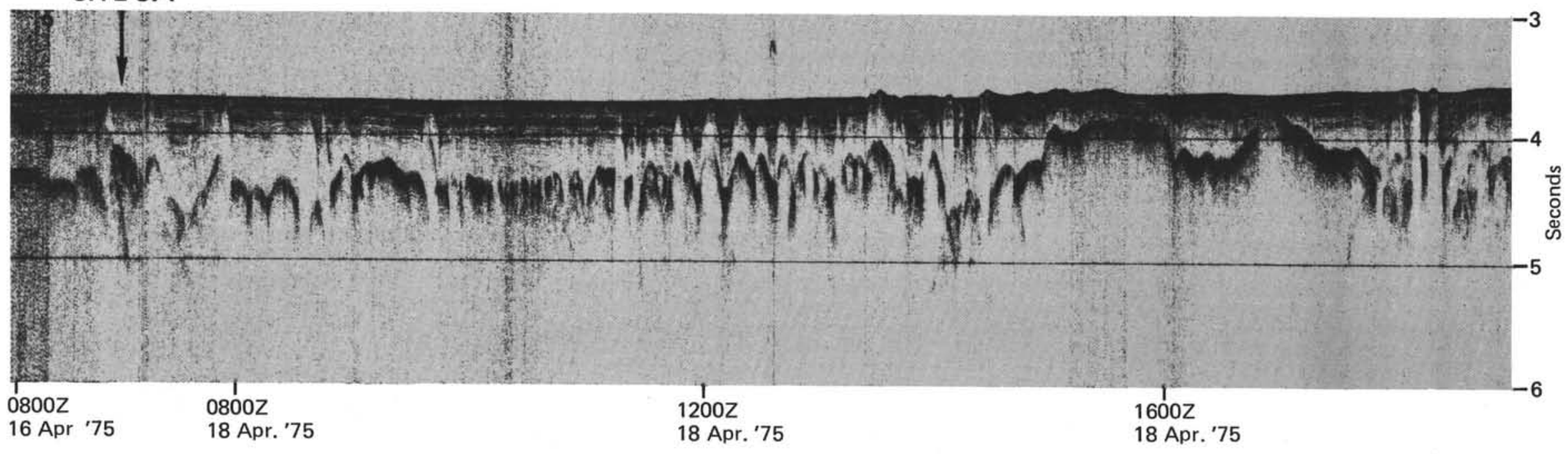

Figure 3-Continued 

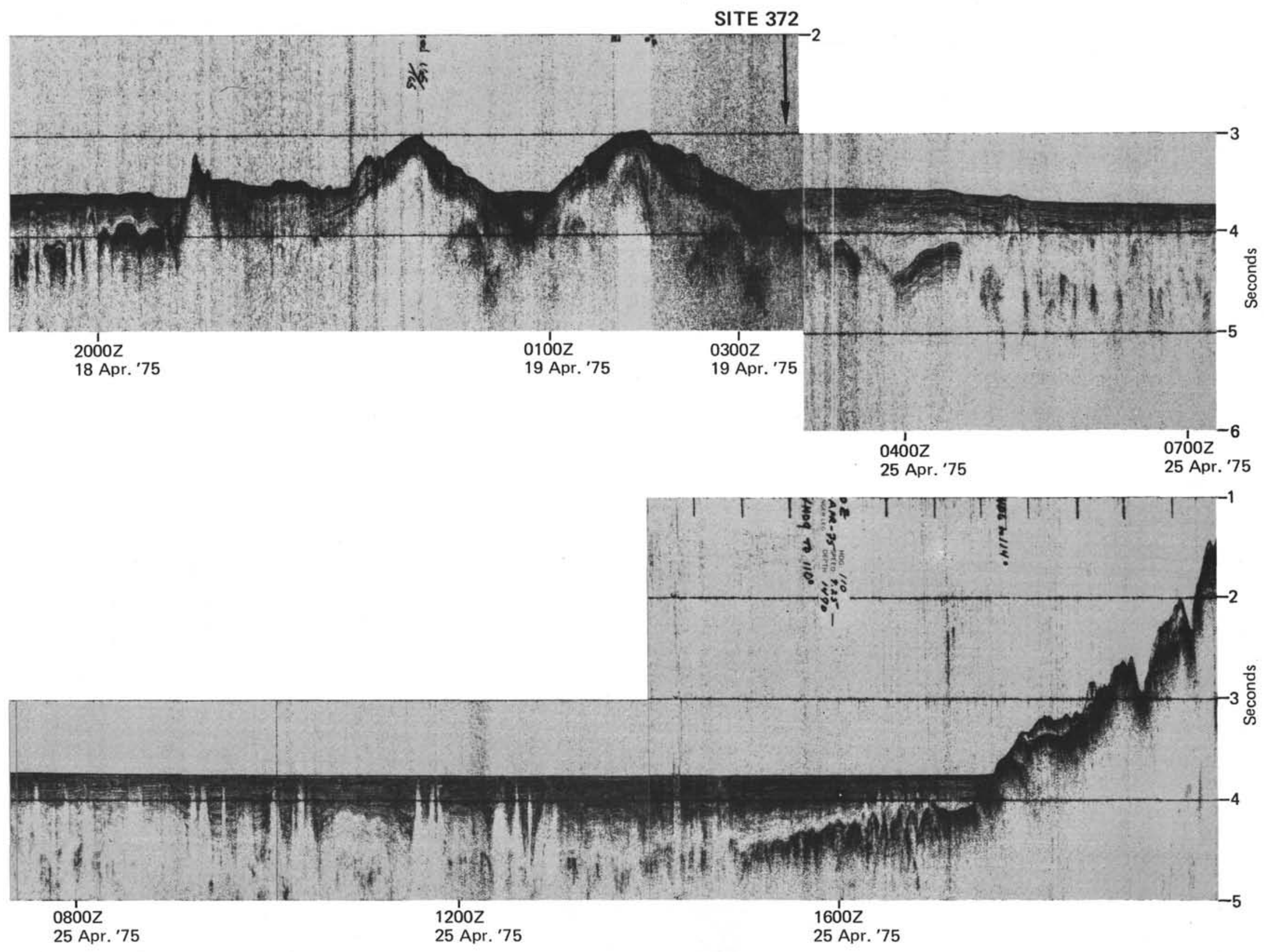


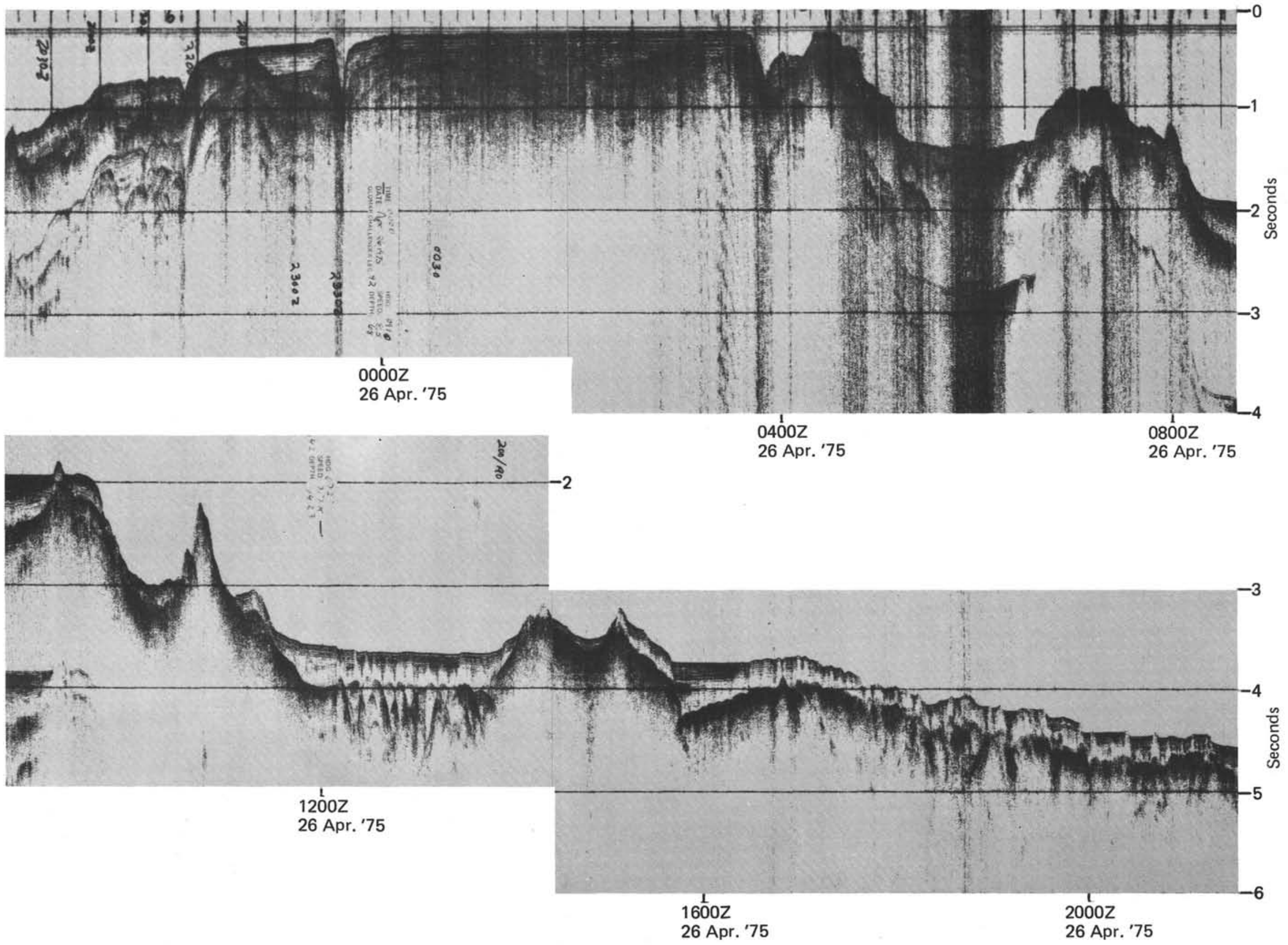

Figure 3-Continued 
SITE 373
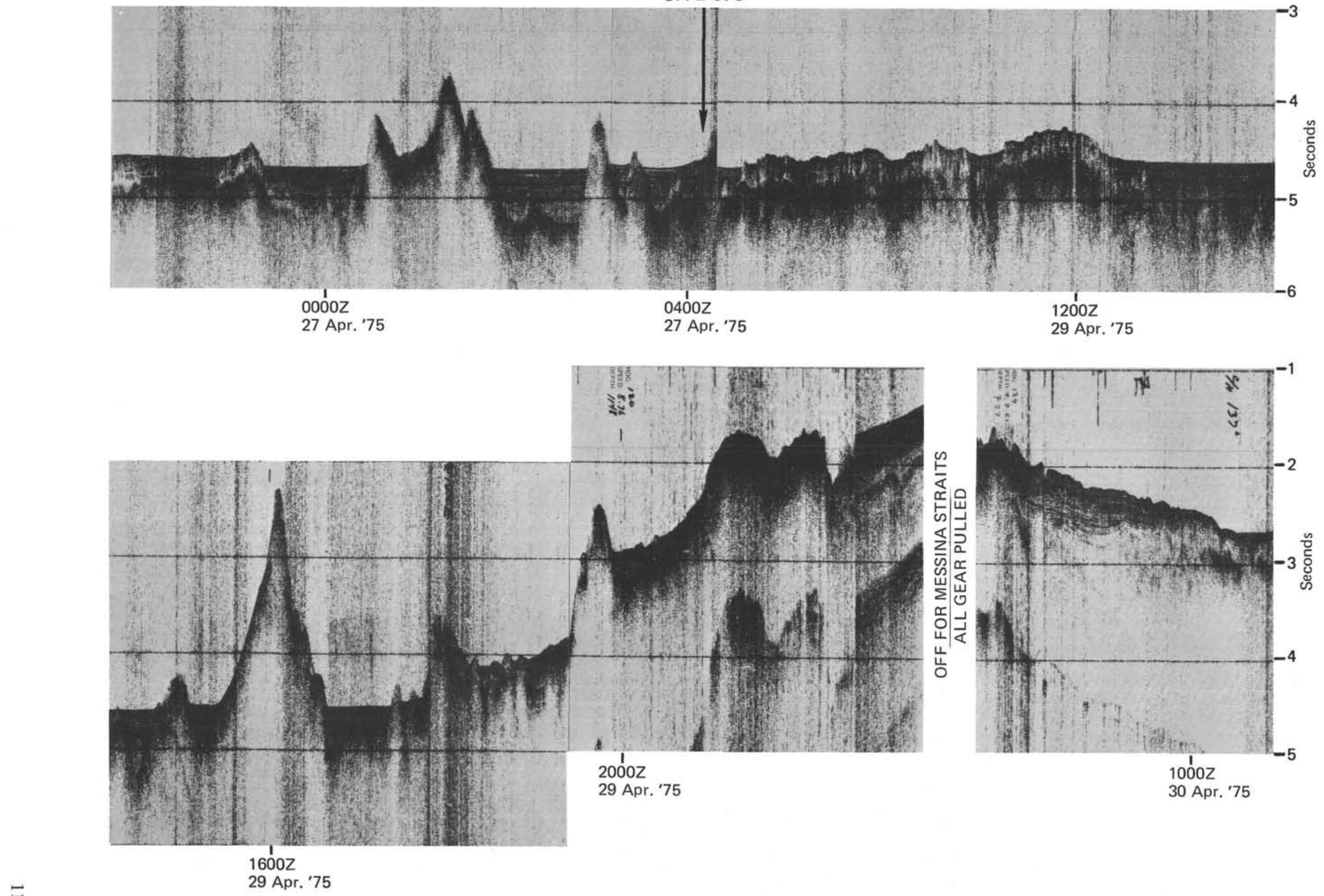

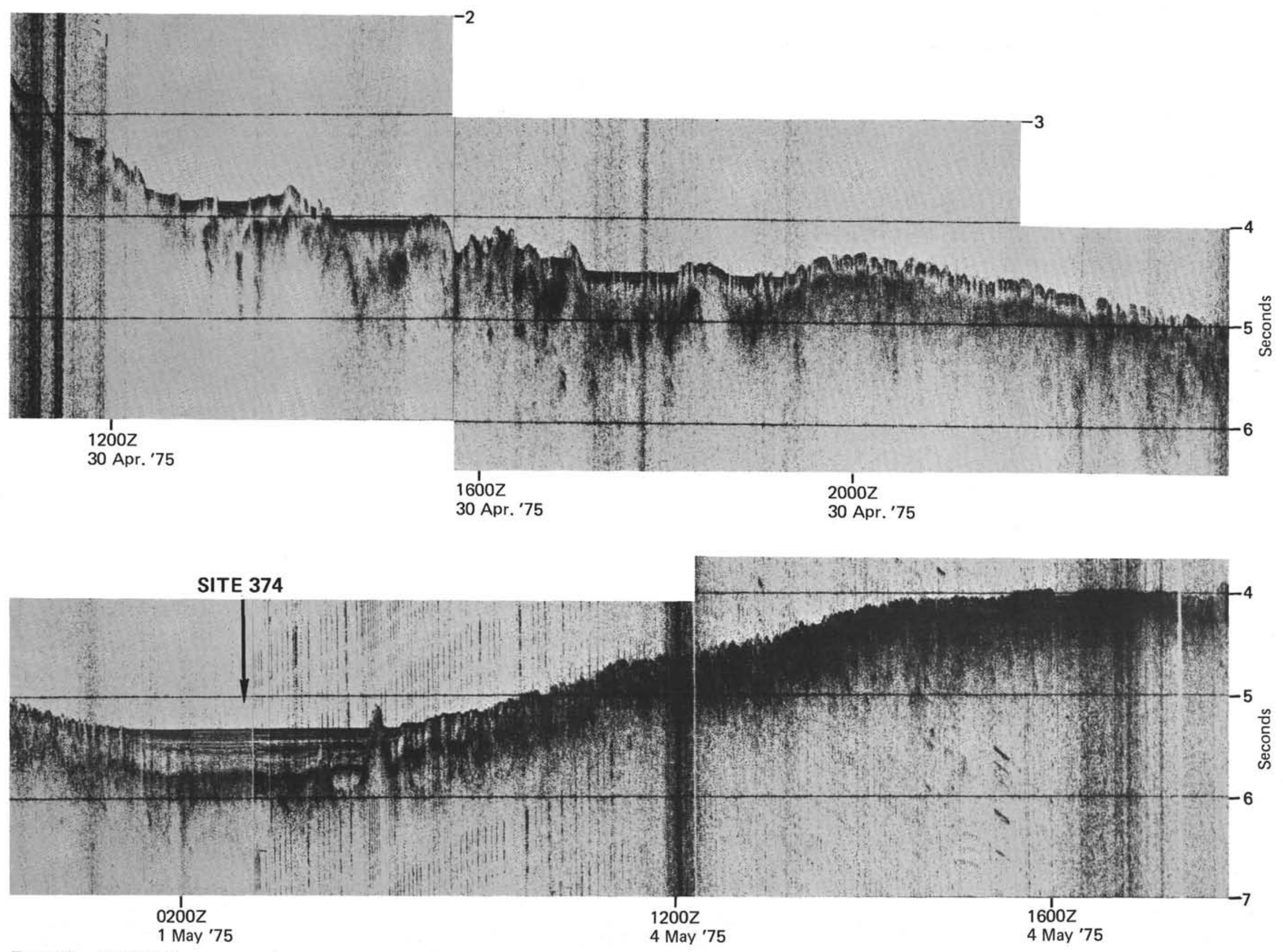

Figure 3-Continued 

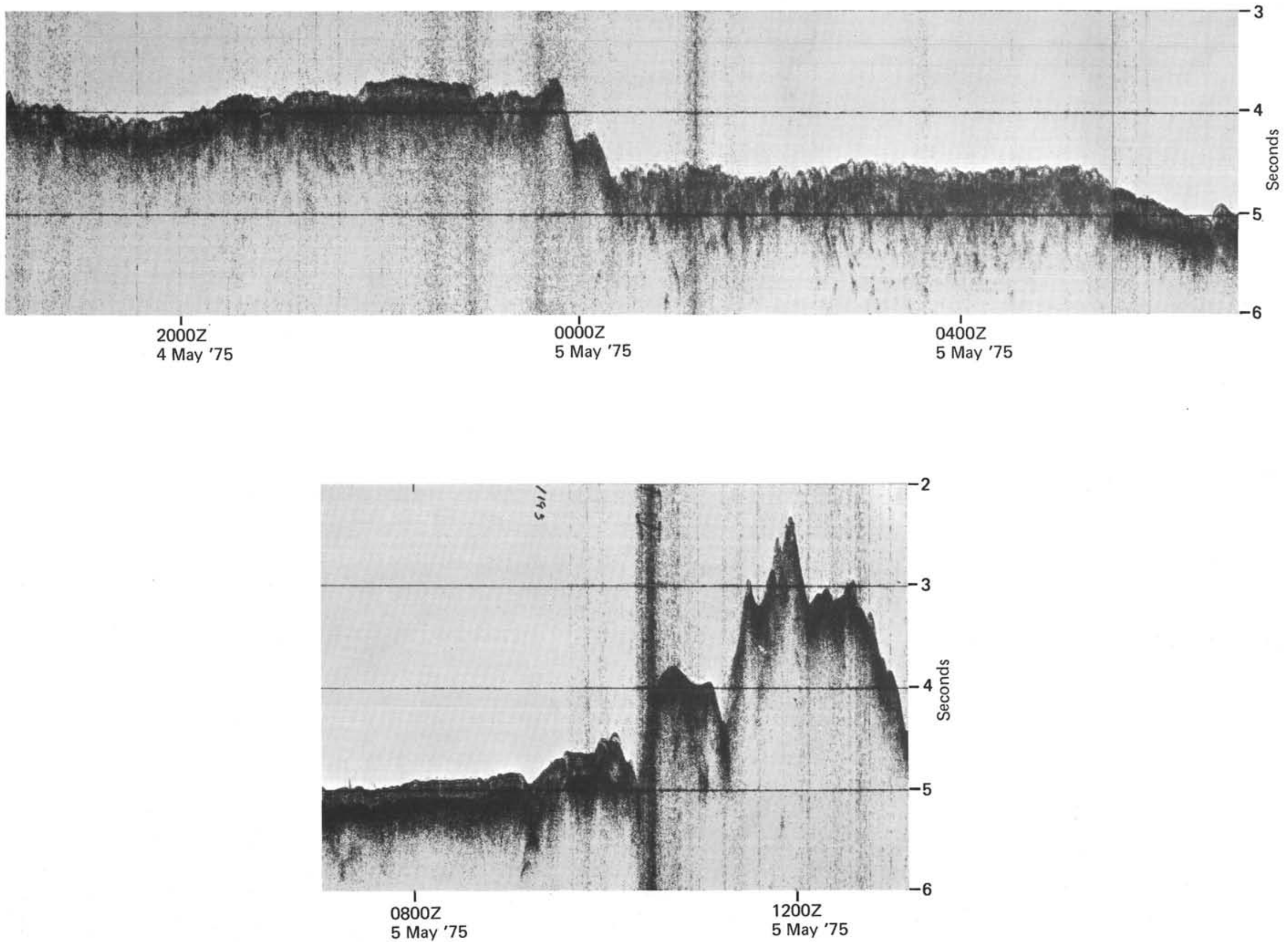

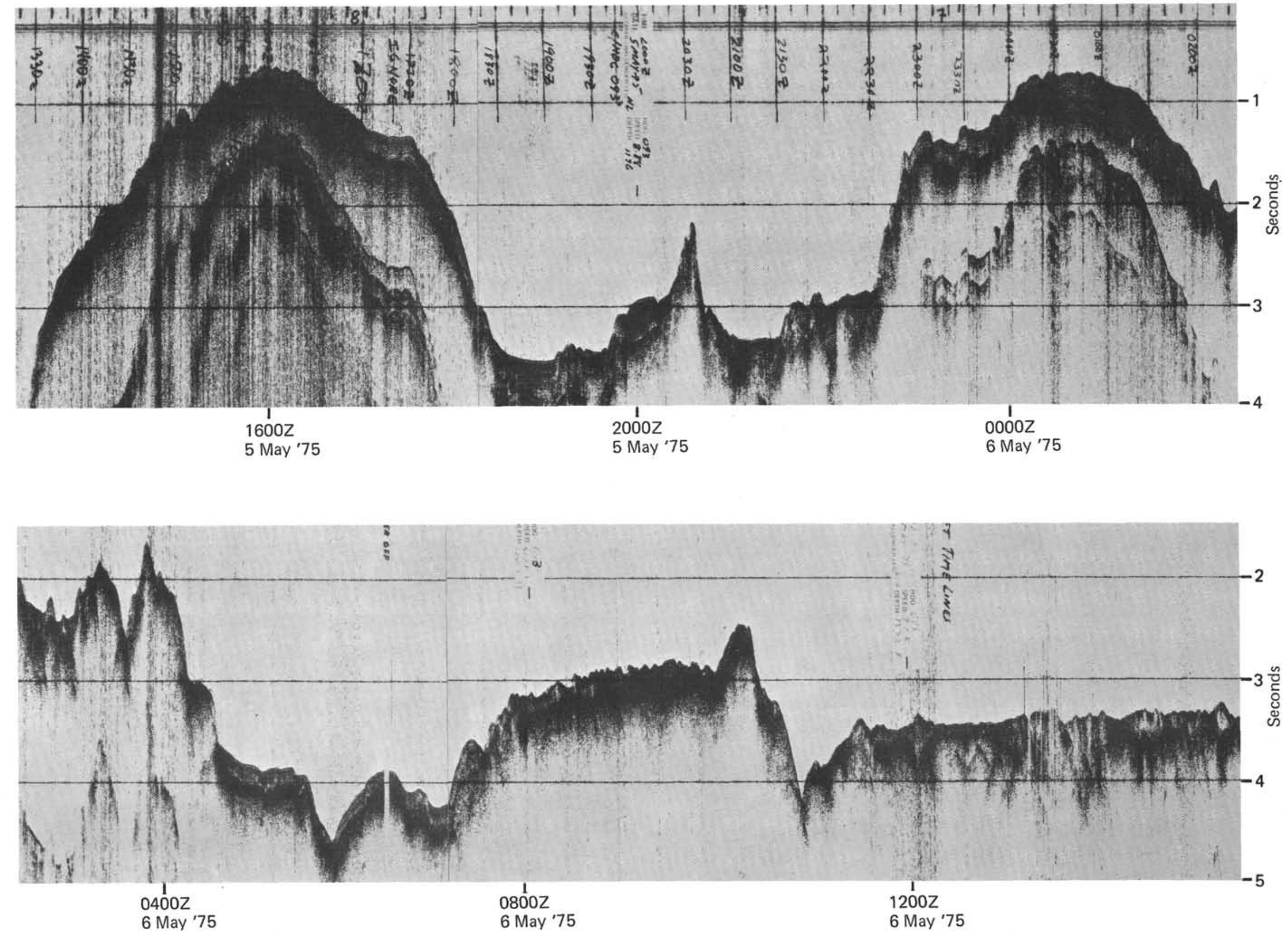

Figure 3 -Continued 

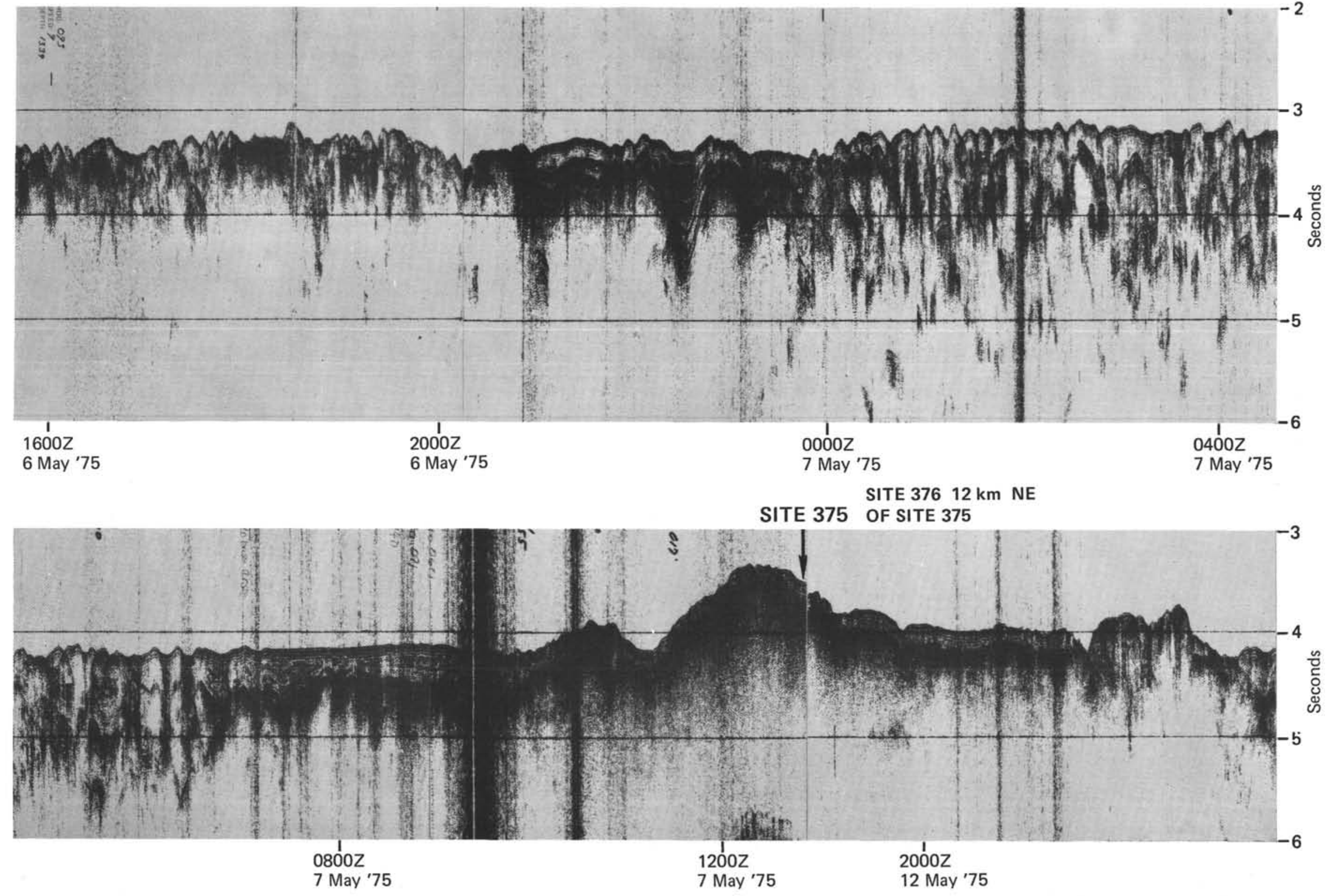

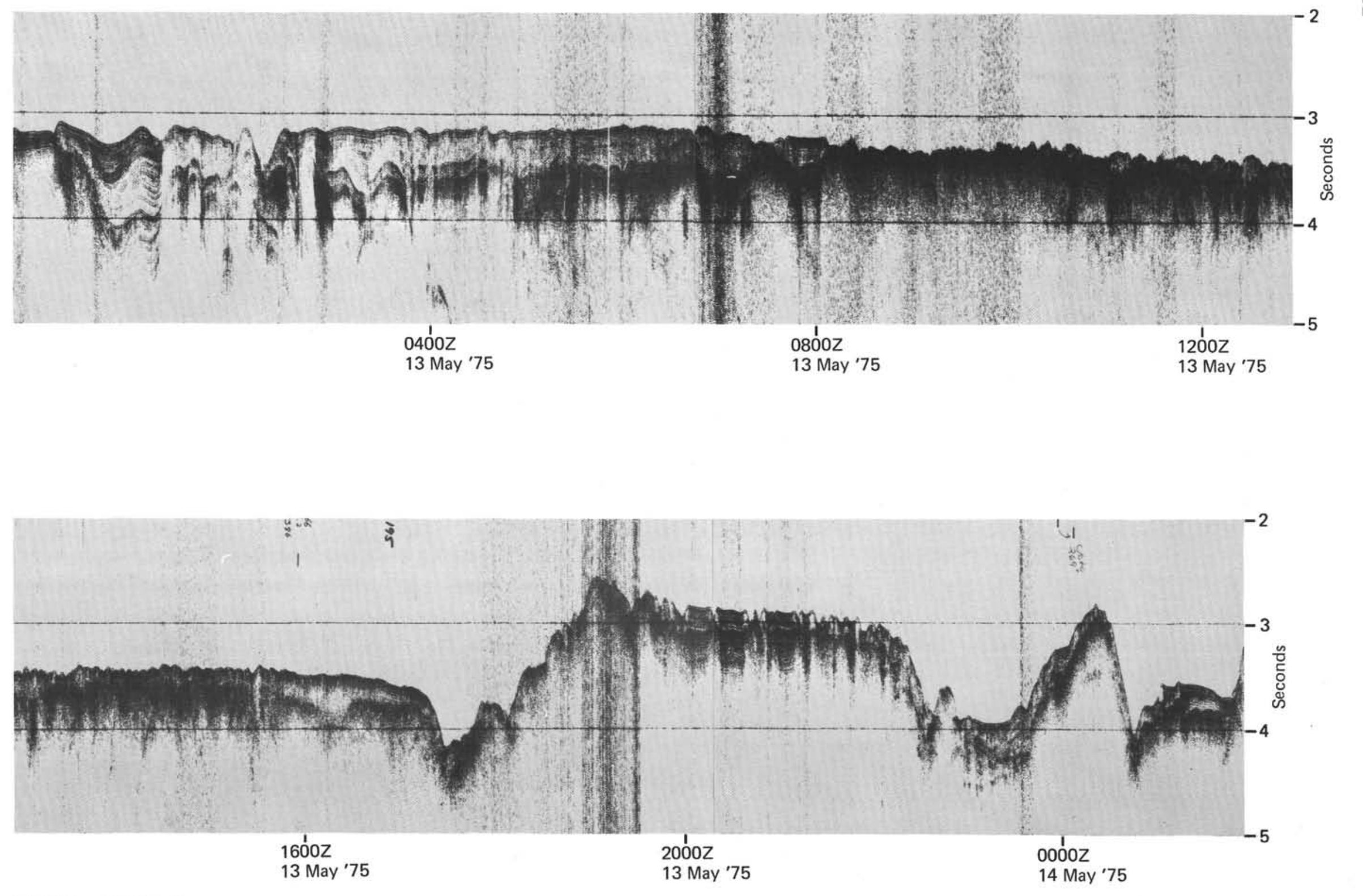

Figure 3 -Continued 


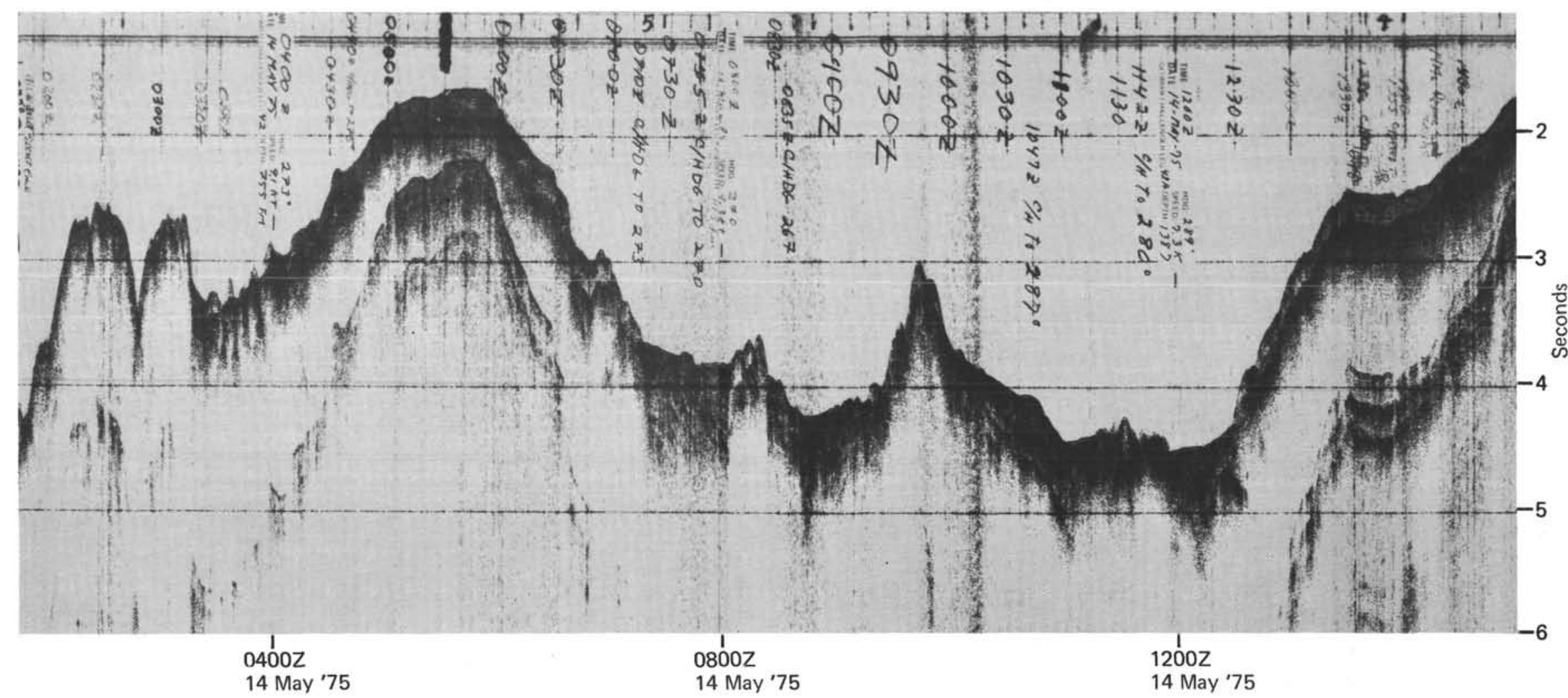

Figure 3-Continued 


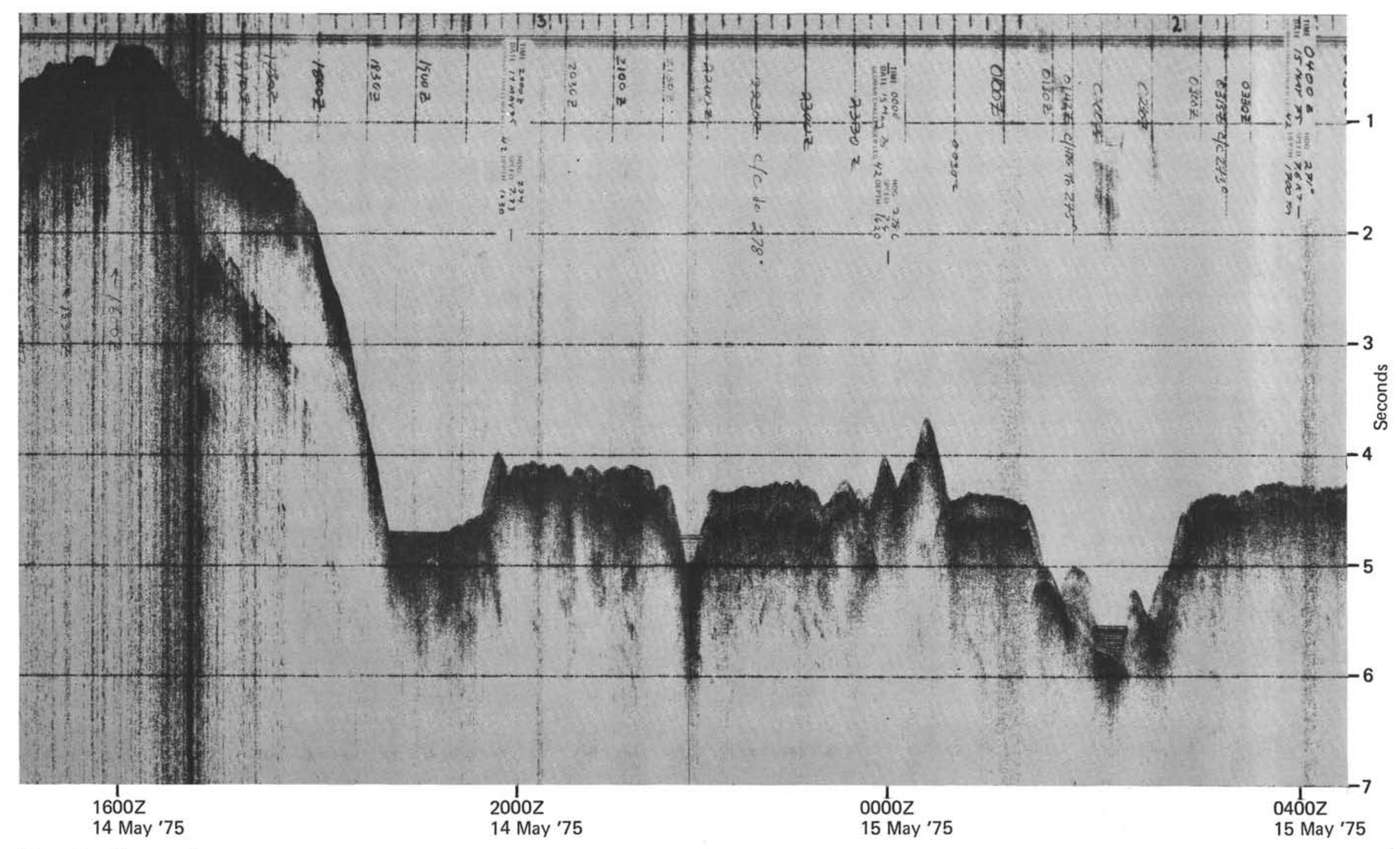

Figure 3 - Continued 


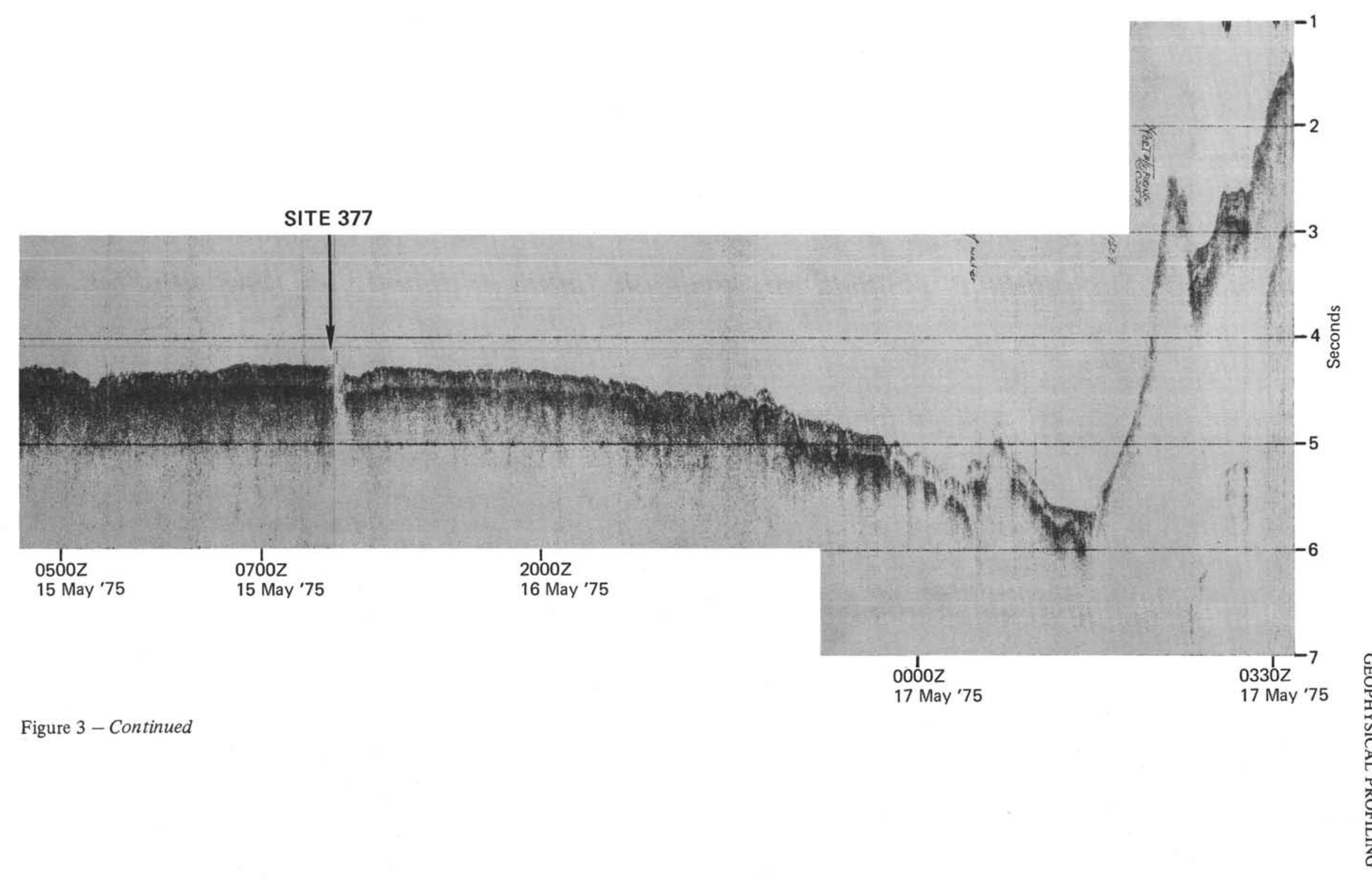


SITE 378
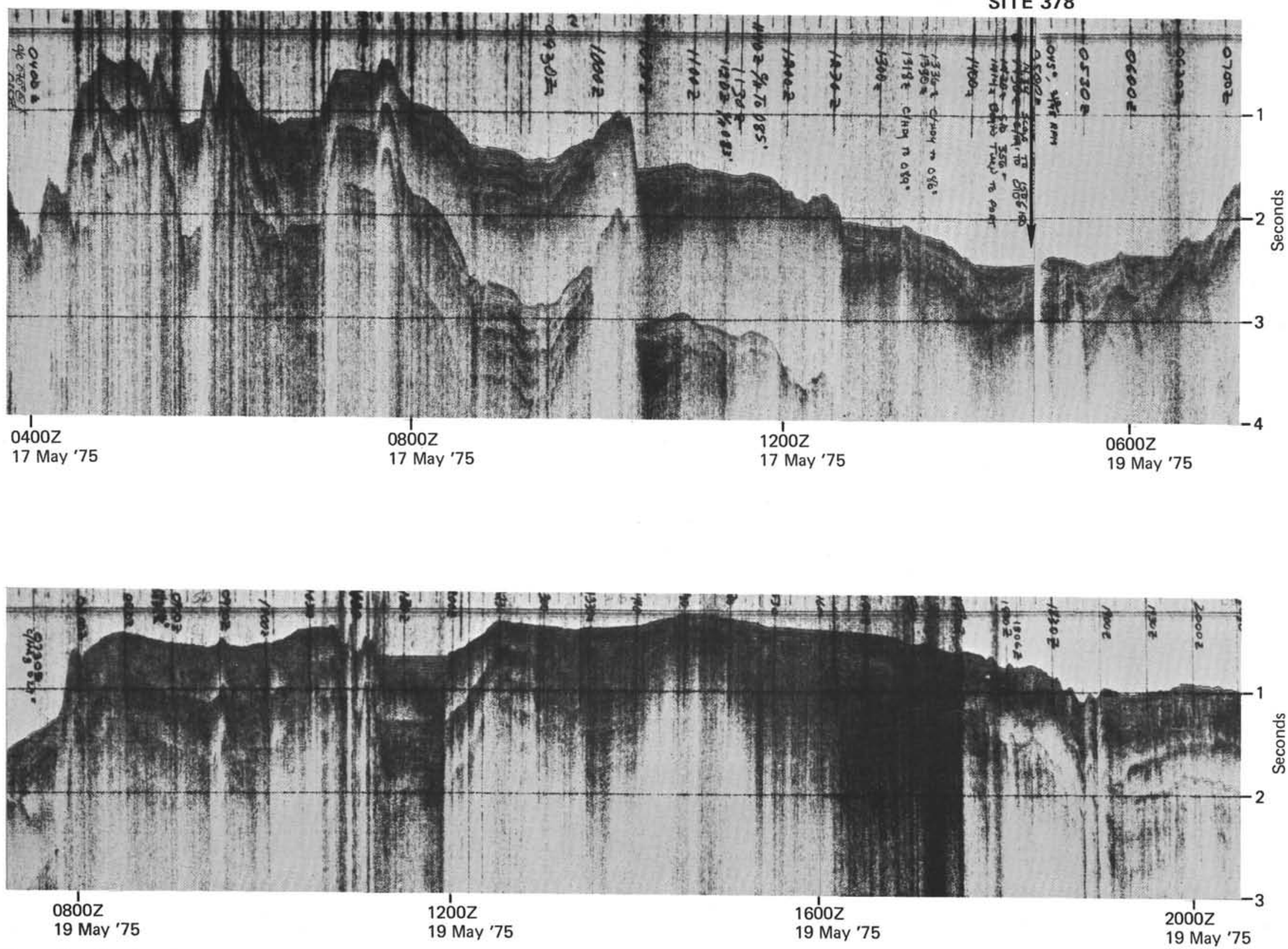

Figure 3-Continued 


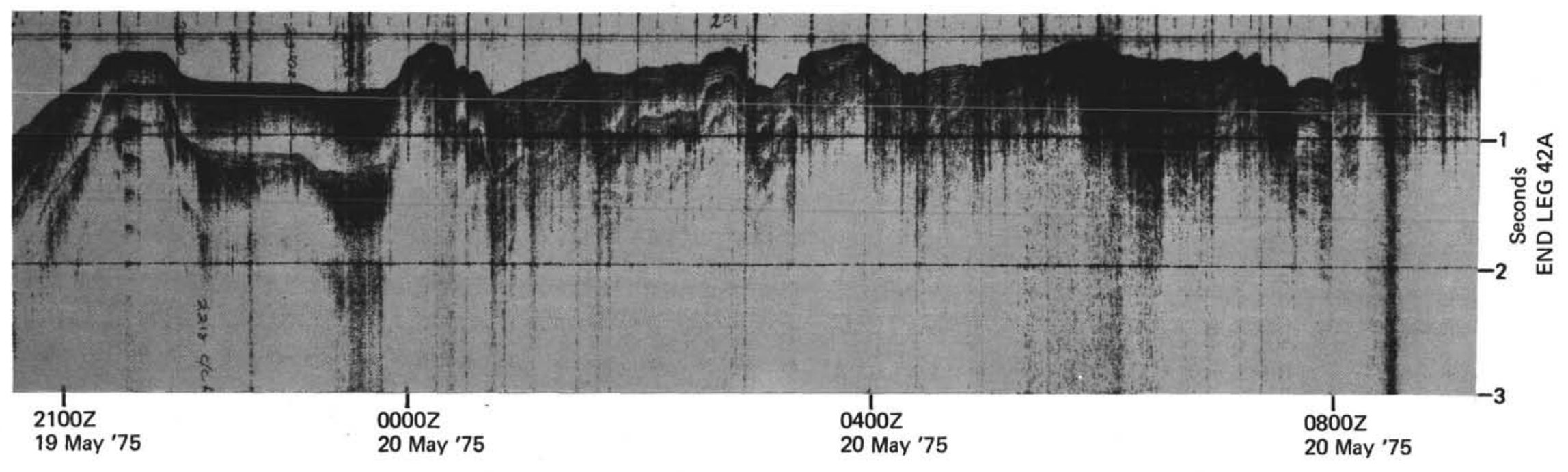

